\title{
La Comintern y la formación de militantes comunistas latinoamericanos
}

\section{The Comintern and the formation of the Latin American Communist militants}

Víctor L. Jeifets*

Lazar S. Jeifets ${ }^{* *}$

\begin{abstract}
Resumen: El artículo analiza los rasgos principales de la política de formación y capacitación de los militantes comunistas de latinoamericana en las escuelas de cuadros fundadas a lo largo de la existencia de la Comintern, en Moscú. Sobre la base de los documentos del Archivo de la Comintern resguardados en Moscú, los autores están recuperando la historia de la presencia latinoamericana en estas escuelas de cuadros, asunto poco reflejado en la historiografia de la izquierda de América Latina del período de la Comintern. El artículo analiza los rasgos básicos del cuerpo de estudiantes latinoamericanos en Moscú, así como los pormenores de su formación y evolución.
\end{abstract}

Palabras clave: Escuela Internacional Leninista, Comintern, política de cuadros, movimiento de izquierda latinoamericano

\begin{abstract}
The article analyzes the main features of the policy of training of Latin American communist militants within the cadre schools in Moscow founded throughout the existence of the Comintern. Basing on documents of the Comintern Archives guarded in Moscow the authors are recovering the history of Latin American presence in these schools which is poorly reflected in the historiography of the Latin American Left-Wing movement in the period of the Comintern. The article analyzes the basic features of the group of Latin American students in Moscow, as well as details of its formation and evolution.
\end{abstract}

Keywords: International Lenin's School, Comintern, personnel policy, Latin American Left-Wing Movement

Recibido: 6 mayo 2016

Aceptado: 30 agosto 2016

\footnotetext{
*Ruso. Doctor titular, profesor de St. Petersburg University y profesor de Saint-Petersburg State University of Aerospace Instrumentation.Autor y coautor de varios libros y artículos sobre relaciones internacionales e historia de la izquierda latinoamericana. jeifets@gmail.com El artículo fue escrito dentro de los marcos del proyecto de investigación patrocinado por la Fundación Estatal Rusa de Humanidades (Fundación Rusa de Investigaciones Fundamentales), proyecto núm. 16-01-00138.

** Ruso. Doctor titular, profesor de St. Petersburg University. Autor y coautor de varios libros y artículos sobre relaciones internacionales e historia de la izquierda latinoamericana. jeifets@gmail.com
} 


\section{Introducción}

En la historia del movimiento internacional de izquierdas, la formación y capacitación de militantes comunistas bajo la tutela de la Comintern, ocupa un lugar importante. El partido comunista mundial, es decir, la III Internacional, necesitaba no solamente militantes activos, sino también gente capaz de seguir las líneas directrices elaboradas por el Estado Mayor de la revolución mundial con sede en Moscú. Varias escuelas de cuadros fueron fundadas en la URSS y sus regiones. Con el objeto de alcanzar tal reto, la Escuela Internacional Lenin (ELI), fue la más importante y la más prestigiosa de ellas. El tema, en sus aspectos generales, ha sido varias veces el objeto de estudio ${ }^{1}$, así como en sus particularidades nacionales ${ }^{2}$. No obstante, la historia del comunismo latinoamericano todavía está llena de lagunas significativas y carece de datos analizados referiéndose a la cuestión de la presencia latinoamericana en las escuelas de cuadros de la Comintern. Las grandes obras sobre el movimiento comunista latinoamericano ${ }^{3}$ no ayudan mucho en este sentido ; en el mejor de los casos, sólo contienen informaciones generales y algunos nombres de los estudiantes latinoamericanos en Moscú, sin profundizar en el estudio del tema. Además, sus autores estuvieron privados del acceso a las fuentes primarias del Archivo de la Comintern, resguardadas en la capital rusa, lo que obviamente se convirtió en un obstáculo enorme para ellos. Varios nombres de los estudiantes latinoamericanos han sido revelados en obras recientes dedicadas a la historia del

\footnotetext{
${ }^{1}$ Leonid Babitschenko. "Die Kaderschulung der Komintern". En : Weber, Hermann et al. (eds.). Jährbuch für Historische Kommunismusforschung (Berlin, 1993) 37-59; Julia Köstenberger. "Die Internationale LeninSchule 1926-1938). En: Michael Buckmiller and Klaus Meschkat (eds.). Biographisches Handbuch zur Geschichte der Kommunistischen Internationale: Ein deutsch-russisches Forschungsprojekt (Berlin: Akademie Verlag, 2007) 287-309; Branko Lazitch. "Les écoles de cadres du Comintern". En: Jacques Freymond. Contributions á l'histoire du Comintern (Genéve: Ed. Librarie Droz, 1965) 233-257; Grigorii Z. Sorkin y Kirill K. Shirinia. "Comintern - escuela de formación internacionalista de cuadros". Voprosy istorii KPSS, núm. 1 (1977), Moscú; A.Kocho-Williams. Stalin's Students: the International Lenin School, 19261938. - http://www.academia.edu/5615677/Stalin_s_Students_the_International_Lenin_School_1926-1938.

${ }^{2}$ Gidon Cohen and Kevin Morgan. "Stalin's Sausage Machine: British Students at the Internatonal Lenin School 1926-37". Twentieth Century British History, vol. 13, N. 4 (2002): 327-355; John Halstead and Barry Mc Loughlin. "British and Irish Students at the International Lenin School 1926-37". Saothar. Yearbook of the Irish Labor History Society, N.22 (1997): 63-79; Julia Köstenberger. Der deutsche Sektor an der KUNMZ in Moskau (1921-1936). Österreicher an einer Sowjetischen Kadershule, Diplomarbeit. Wien: Universität Wien, 1999; Jonni Krekola. A Short Course of Stalinism: Finns at the International Lenin School, Moscow, 1926-1938. Doctoral Dissertation, https://helda.helsinki.fi/handle/10138/11969; Alexander Pantsov and Daria Spiachak. Chinese Students at the International Lenin School in Moscow, 1926-1938: Light from the Russian Archives. E-book, vol. 81 (2014)

http://booksandjournals.brillonline.com/content/books/b9789004282278_025; A.A.Sokolov. Comintern i Vietnám. La Preparación de los cuadros politicos vietnamienses en las escuelas superiores comunistas de la URSS. Los años '20-'30. (Un ensayo histórico y político (Moscú: Institut Vostokovedeniia RAN, 1998).

${ }^{3}$ Robert J. Alexander. Communist Party of Venezuela (Stanford: Hoover Institution Press, 1969), Boris Goldenberg, Kommunismus in Lateinamerika (Stuttgart/Berlin/Köln/Mainz: W.Kohlhammer, 1971); Manuel Caballero. Latin America and the Comintern (Cambridge: Cambridge University Press, 1987).
} 
comunismo de esta región ${ }^{4}$, sin embargo, estos trabajos tampoco contienen un estudio sistemático del tema de las escuelas de cuadros de la Comintern en Moscú.

Las principales preguntas analizadas aquí son: ¿quienes eran los estudiantes latinoamericanos de las escuelas de cuadros en Moscú?, ¿qué curriculum tenían que asumir?, ¿cómo estuvieron representados diferentes partidos del subcontinente en estas escuelas? Y, no menos importante ¿Cuál es el balance de los doce años de estudios de los militantes comunistas latinoamericanos en la Meca revolucionaria? Consecuentemente, creemos necesario matizar y profundizar esta área de investigación. Partimos del planteamiento respecto de la importancia de la inserción internacional de la izquierda latinoamericana y su enlazamiento con la Comintern, e intentamos recuperar los datos históricos significativos sobre la presencia latinoamericana en las escuelas de cuadros del partido comunista mundial.

Analizaremos cómo y de que países llegaron estudiantes latinoamericanos a Moscú para ingresar a la ELI u otras instituciones de educación partidaria. Para formar la imágen de este 'cuerpo estudiantil', investigaremos si existían razgos comunes entre los integrantes del grupo latinoamericano y, asimismo, definir las particularidades de este grupo. Sabremos si las escuelas cominternistas de cuadros realmente contribuyeron a la formación de los futuros dirigentes partidarios de los P.Cs latinoamericanos. Cabe hacer notar que el objeto de estudio son las escuelas del período de la Comintern, pues las escuelas similares de después del fin de la Segunda Guerra Mundial, desarrollaron sus actividades en ambiente histórico diverso, con otros profesores y -lo más importante - con diferente carácter de relaciones entre los partidos comunistas. Por lo mismo, estas últimas no serán objeto en el presente texto. Como hemos mencionado, gran parte de los estudios anteriores carecieron de las fuentes primarias del Archivo de la Comintern (RGASPI, por sus siglas en ruso), de modo que uno de los retos para nuestro estudio fue recuperar los datos necesarios, en este significativo lugar.

Para alcanzar nuestros objetivos, hemos elaborado un texto dividido en tres secciones. En la primera, nos concentraremos en los orígenes de la política de cuadros realizada por la Comintern. En esta parte destacaremos la formación de la ELI y de la Universidad Comunista de Trabajadores del Oriente (KUTV, por sus siglas rusas). En la segunda sección, investigamos los inicios de la presencia latinoamericana en las escuelas de cuadros en Moscú. Abordaremos los detalles del envio de los alumnos latinoamericanos a la URSS y la distribución de las plazas entre los partidos de las diferentes naciones latinoamericanas. En la tercera sección, nos ocuparemos de formar la imágen general del cuerpo de estudiantes latinoamericanos en las escuelas cominternistas de cuadros. Por lo

\footnotetext{
${ }^{4}$ Lazar Jeifets, Víctor Jeifets y Peter Huber. La Internacional Comunista y América Latina, 1919-1943. Diccionario biografico (Moscú: Instituto de Latinoamerica de la Academia de Ciencias / Ginebra: Institut pour l'histoire du communisme, 2004); Klaus Meshkat y Jorge María Rojas. Liquidando el pasado: La izquierda colombiana en los archivos de Moscú (Bogotá: Ed. FESCOL, 2009); Olga Ulianova y Alfredo Riquelme. Chile en los archivos soviéticos. Tomo 1. Chile y Komintern 1922-1931 (Santiago: Ed. LOM, 2005); tomo 2. Chile y Komintern 1931-1935 (Santiago: LOM, 2009); Olga Ulianova (ed.). Políticas, redes y militancias. Chile y América Latina en el siglo XX (Santiago: USACH-Ariadna, 2009); Olga Ulianova, Manuel Loyola y Rolando Álvarez (eds.). 1912-2012: El siglo de los comunistas chilenos (Santiago: Ariadna, 2012).
} 
último, nos enfocaremos al balance de la importancia de los estudios de los militantes latinoamericanos en Moscú, para sus carreras partidarias.

Utilizamos, como fuentes, algunas memorias de militantes comunistas, aunque, para este tema, son realmente pocas. Sin embargo, la base principal del artculo son los documentos de los archivos rusos, los materiales de la ELI, la correspondencia entre los órganos de la Comintern con los Partidos Comunistas latinoamericanos y los secretariados y burós regionales de la III Internacional en América Latina. La base principal para nuestro estudio, son los datos contenidos en las carpetas personales de los militantes comunistas resguardadas en RGASPI.

Obviamente, no podemos limitarnos a la enumeración de nombres y países latinoamericanos representados en las escuelas de cuadros cominternistas. Es importante cotejar estas listas con otros documentos producidos por la Comintern, averiguando los nombres verdaderos, intentando entender que país fue representado por tal o cual estudiante. Comparando y cotejando las fuentes del archivo con la información publicada en la bibliografia existente y las memorias, entenderemos de manera adecuada los pormenores de la historia de la presencia latinoamericana en la ELI Tras revisar cuantos estudiantes latinoamericanos estaban cursando materias en Moscú, tenemos que hacer un balance final del impacto de las escuelas de cuadros en la formación de la militancia de izquierda en el subcontinente.

\section{Los orígenes de la política de cuadros de la III Internacional}

La Comintern, como partido único de la revolición, tuvo por meta la formación, en clave bolchevique, de los dirigentes de las secciones nacionales del mismo, por tanto, fue de su interés tanto la rápida formación de organizaciones comunistas "como partidos de nuevo tipo", como su fortalecimiento político, ideológico y organizativo. Según los destacados investigadores soviéticos, Grigorii Sorkin y Kirill Shirinia, todas las instituciones de la III Internacional contribuían al trabajo de educación ideológica y política, refiriéndose con ello no solamente a los secretariados regionales y centrales, sino también, a los congresos y a los plenos ampliados del CEIC ${ }^{5}$. Eso permitía involucrar a gran número de funcionarios del partido en la discusión de los asuntos políticos relevantes. En la formación de los cuadros internacionales desempeñaba, un papel de importancia desempeñó la red de las instituciones internacionales bajo la dirección del CEIC, que incluía a la Escuela Internacional Lenin (ELI), a la Universidad Comunista de los Trabajadores de Oriente (KUTV), a la Universidad Comunista de Minorías Étnicas del Occidente (KUNMZ), y otras.

El partido bolchevique había comenzado a capacitar a futuros dirigentes desde los años de la guerra civil en Rusia y, en primer lugar, debió cumplir con esta tarea en las regiones periféricas de la URSS. Para este propósito, se fundaron varias escuelas superiores

\footnotetext{
${ }^{5}$ Grigorii Z. Sorkin and Kirill K. Shirinia. "Comintern - escuela de formación internacionalista de cuadros". Asuntos de historia del PCUS. N1 (1977): 70; N.N. Timofeeva. Universidad Comunista de los Trabajadores de Oriente (KUTV) (1921-1925). Narody Azii i Afriki. № 2 (1976); N.N. Timofeeva. Universidad Comunista de los Trabajadores de Oriente (KUTV) (1926-1938). Narody Azii i Afriki. № 5 (1979).
}

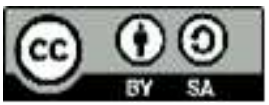


comunistas. Durante la fase inicial de este trabajo, la institución educacional básica fue la KUTV, fundada en abril del año 1921. Su tarea consistió en la preparación de los funcionarios partidarios y soviéticos para "las repúblicas autónomas, comunas laborales y minorías étnicas" ". El primer rector de la KUTV, el vice-Comisario del Pueblo para los Asuntos de Nacionalidades, Grigorii Broido, estimó necesario disponer para los trabajadores de otros países, un tipo de poder soviético que correspondiera a las particularidades de su modo de vivir y a las condiciones históricas específicas de cada nación, capacitando a "los comunistas conscientes, conocedores del marxismo teórico, y los líderes revolucionarios" $"$.

Tras la creación en la citada universidad, a finales del año 1922, del "grupo extranjero", las tareas y funciones de la KUTV se ampliaron de manera sustancial y la institución empezó a preparar funcionarios para los Partidos Comunistas de los países que, según la clasificación de la III Internacional, pertenecían a colonias y semicolonias. Sin embargo, aquellos partidos no eran los únicos que carecían de cuadros marxistas. Varias organizaciones de otras latitudes que disponían de gran cantidad de militantes de base, sufrían también la escasez de funcionarios de diferente nivel que conocieran de marxismo y de mecanismos de organización partidaria. Obviamente, donde más se notaban estas carencias, era en los partidos jóvenes de los países del Oriente y de América Latina, donde las tradiciones del movimiento obrero organizado eran casin inexistentes. Según cuenta el Secretario General del Partido Comunista de México (PCM), Rafael Carrillo Azpetia, leyó por primera vez el Manifiesto Comunista de Marx y Engels, durante su visita a Moscú en 1923, a pesar de que, para este año, ya había encabezado, por un par de años, la Federación de Jóvenes Comunistas de México (FJCM) y era miembro del CC del Partido Comunista ${ }^{8}$. Dentro del PCM, Carrillo Azpeitia tenía la reputación de político bien capacitado y experimentado y, efectivamente lo era, comparado con la mayoría de los militantes.

Tomando en cuenta esta situación, el IV Congreso de la Comintern, persiguiendo el fin de "profundizar la formación marxista y la educación comunista práctica", decidió organizar cursos internacionales de capacitación para los militantes de diferentes secciones nacionales. Estos cursos tendrían que convertirse en la cúspide de la pirámide del sistema de escuelas partidarias de las secciones nacionales ${ }^{9}$. Esta idea no fue realizada de una vez: se formalizó y concretizó por el V Congreso de la IC, el que tomó la decisión de empezar la capacitación de los cuadros de las secciones más grandes e influyentes de la III Internacional. Según los acuerdos establecidos, los partidos alemán, británico, francés, checoeslovaco, italiano, estadounidense y algunos otros, debían comisionar a varios

\footnotetext{
${ }^{6}$ Izvestia de TsK RKP /b/. No 31 (1921): 12.

${ }^{7}$ Grigorii Broido. "La Universidad Comunista de los Trabajadores de Oriente". Vida de naciones, N¹1 (1921). Citado en: A.A. Sokolov. Comintern y Vietnam. Preparación de los cuadros políticos vietnamienses en las escuelas superiores comunistas de la URSS. Años '20-'30. (Ensayo histórico-político) (Moscú: Institut Vostokovedeniia RAN, 1998) 14.

${ }^{8}$ R. Carrillo. "Memoria roja de los años veinte. El testimonio de Rafael Carrillo". Memoria. México, No 92 (1992): 52-59.

9 'Deyatelnost' Kommunisticheskij partii v dele formirovaniia i podgotovki. Resheniie IV Kongressa Kominterna”. En: Kommunisticheskii Internatsional v dokumentaj. 1919-1932 (Moscú: Partiinoie izdatelstvo, 1933) $336-337$.
} 
miembros suyos para viajar a Moscú a estudiar la teoría y práctica de marxismoleninismo $^{10}$. Esta decisión impulsó la creación de la ELI que, en adelante, se convirtió en la más prestigiosa de las tres principales escuelas de cuadros de la Comintern. La última convocatoria de estudiantes de comunistas que actuaban de manera legal (incluyendo los de América Latina), tuvo lugar en $1936^{11}$.

El 9 de octubre de 1924, el Buró de Organización del CEIC tomó la decisión de organizar los Cursos Internacionales Superiores de dos años, para 40 personas. En 1925 la cantidad de estudiantes aumentó a 70 personas, entre ellas, 9 procedían de Alemania, 8 de Francia, 8 llegaron de Inglaterra, 7 de los EE.UU., 7 de Checoeslovaquia, 6 de Italia, 9 de los países escandinavos. Polonia, Japón, China, India, Egipto e India Holandesa, enviaron 2 personas cada uno. Austria, Bélgica, España, Holanda, Yugoslavia, Bulgaria, Turquía, Irán, Siria y África del Norte, comisionaron 1 estudiante cada uno. Para los países de América Latina, las cuotas no fueron designadas, lo que demuestra su posición periférica en la percepción de los dirigentes de la Internacional ${ }^{12}$.

El VI Pleno Ampliado del Comité Ejecutivo de la Comintern (febrero-marzo de 1926), dió un nuevo impulso a los esfuerzos para crear los Cursos Leninistas Internacionales que, según las palabras de uno de los dirigentes de la Internacional, el húngaro Béla Kun, tenían como objetivo formar los dirigentes "de manera leninista y bolchevique, para que entiendan el carácter y las contradicciones de la época histórica actual, y sean capaces de vadear en la situación histórica concreta de sus propios países y de distinguir de manera dialéctica entre los elementos clave de revolución rusa -que son comunes y convenientes para todos los países- y los elementos que no son especícamente rusos". Con eso subrayaba que sólo tras cumplir esta tarea, la bolchevización de los partidos comunistas obtendría fundamento sólido ${ }^{13}$. La Escuela empezó sus labores en marzo de $1926^{14}$.

La selección de alumnos para la escuela era bastante rigurosa. Sólo un militante con experiencia de trabajo partidario no menor a un año y que perteneciera a los órganos dirigentes distritales, regionales o centrales de su PC, podía aspirar a ser estudiante en la ELI. Los preferidos eran los obreros de grandes fábricas y los obreros agrícolas. Cada partido tuvo una cuota, y a ningun partido se le aceptó que los enviados que no fueran obreros insdustriales sobrepasaran el $15 \%$ de la cuota. La entrada de intelectuales, funcionarios, campesinos y artesanos a la escuela, fue limitada.

\footnotetext{
${ }^{10}$ Piatyi Mirovoi kongress Kommunisticheskogo Internatsionala. 17 iyunia-8 iyuilia 1924 g. Stenograficheskii otchet. Parte 2 (Leningrado: Gosizdat, 1925) 101.

11 "Decisión del Secretariado del CEIC". Moscú, 9 de octubre de 1924. Rossiiskii Gosudarstvennyi arjiv sotsial'no-politicheskoi istorii (RGASPI). Moscú. F. 495, inv. 18, exp.1109, f.13; Branko Lazitch. "Les écoles de cadres du Comintern”. En: Jacques Freymond (ed.). Contributions á l'histoire du Comintern (Genéve: Librarie Droz, 1965) 233-257; Leonid Babitschenko. "Die Kaderschulung der Komintern". En: Weber, Hermann et al. (eds.). Jährbuch für Historische Kommunismusforschung (Berlin, 1993) 37-59.

12 “El acuerdo del Buró Organizativo del CEIC". Moscú, 9 de octubre de 1924. RGASPI. F. 531, inv. 1, exp.1, f. 24.

13 “Oficio de Béla Kun al Presidium del CEIC”. Moscú, 3 de octubre de 1925. RGASPI. F. 495, inv. 30, exp.69, f. 1.

14 Grant M. Adibekov, Eleonora N. Shakhnazarova, Kirill K. Shirinia. Estructura organizativa de la Comintern. 1919-1943 (Moscú: Rosspen, 1997) 127-128.
} 
Los aspirantes a ser estudiantes de la ELI tenían que demostrar su participación activa en el movimiento revolucionario (en la organización de huelgas, manifestaciones, etc.) o en el trabajo sindical. Al tener esta procedencia, estaban en mejores condiciones para la lucha contra del 'oportunismo' en sus respectivos partidos. Las reglas de admisión rechazaban a aquellos militantes que no hubieran demostrado firmeza revolucionaria después de salir de la cárcel, o que hubiesen mostrado debilidad ante la policía y en los procesos judiciales. Esta misma norma reglamentaria excluía a los militantes que habían participado en las 'luchas sectarias' contra la Comintern y sus secciones nacionales. Los requisitos de nivel de alfabetización no eran altos: los futuros alumnos debían, por lo menos, saber leer y escribir, ser capaces de estudiar y tener conocimientos básicos acerca de la política contemporánea.

Inicialmente los profesores y los alumnos de la ELI se comunicaban en francés, inglés, alemán y ruso, de manera que los alumnos tenían que demostrar nivel avanzado de conocimiento de alguno de estos idiomas. A finales de la década de los 20 , los requisitos de alfabetización para los aspirantes a la ELI fueron reducidos bruscamente a causa de la campaña de "proletarización" de los partidos. Al leerse varios documentos del Archivo de la Comintern, en particular, las autobiografías escritas por los militantes, los fácilmente se revela el precario nivel de alfabetización de ellos. A menudo es necesario leer algunos de estos documentos en voz alta, para poder entender el sentido, porque en el texto hay muchísimas faltas de ortografía que dificultan su comprensión.

Localmente, estos requisitos eran aún más bajos. Así, por ejemplo, el Secretario del Secretariado Sudamericano de la Comintern (SSAIC), al recordar a los comunistas peruanos sobre la posibilidad de enviar un representante a Moscú, dijo que éste "debe ser obrero o campesino, que conozca las cuatro operaciones elementales y poseedor de un espíritu revolucionario a prueba. Debe ser sano: el cambio de clima podría perjudicarle, y tener de 20 a 55 anos de edad"

La información política en la escuela fue organizada de manera dosificada: los estudiantes no podían recibir periódicos ni literatura política. Como resultado, ellos no disponían de información actualizada sobre los países extranjeros y tenían que contentarse con los datos que habían pasado por la censura de la Comintern. Las visitas de los familiares estaban estrictamente prohibidas, así como la comunicación con los ciudadanos soviéticos fuera del control de los profesores de la Escuela. Al respecto, el ex-alumno de la ELI, el mexicano Evelio Vadillo, contaba que un amigo le decía:

llevaba la ilusión de conocer la vida del pueblo y del trabajador rusos y de mirar con sus propios ojos las maravillas que se decía había realizado el gobierno de Stalin. Pero sufrió su primera decepción secreta: ni él ni los demás alumnos tenían contacto alguno con la vida rusa común y corriente, sino que vivían como en un claustro, aislados, como los internos de los viejos seminarios católicos, o más aún quizá. Formaba parte de una casta separada, privilegiada sin duda, pero evidentemente controlada y vigilada también. A pesar de todo, sus convicciones

15 "Carta de V. Codovilla a R. Martínez de la Torre”. Buenos Aires, 29 de marzo de 1929. RGASPI, F. 495, inv. 118, exp.6, f. 11. 
comunistas eran tan fuertes y arraigadas, que fue el mejor alumno de su promoción y se le declaró stajanovista de la Sección Hispanoamericana de la cual se le designó jefe ${ }^{16}$.

Los estudiantes no tenían derecho a comentar, ni siquiera a sus familiares y allegados, nada sobre los estudios en la escuela. Los Partidos Comunistas tenían que enviar a sus estudiantes de forma reservada $y$, para mayor confidencialidad, los alumnos adoptaban seudónimos mientras estudiaban en la ELI. En algunos casos, incluso llegaron con pasaportes falsos.

\section{La inscripción de los latinoamericanos en las escuelas de cuadros}

El primer representante latinoamericano fue enviado a Moscú en el verano de 1926. El secretario del Secretariado de países hispanoparlantes del CEIC, el italiano Palmiro Togliatti, propuso al Secretariado Sudamericano, con sede en Buenos Aires, comisionar a un estudiante para un curso preparatorio, pudiendo el propio SSAIC elegir de qué partido sacarlo $^{17}$. El delegado del Partido Comunista de Argentina (PCA) ante el CEIC, Victorio Codovilla, presentó la candidatura del argentino "Juan Blanco" (en realidad, Antonio Kantor, trabajador joyero y militante del PCA desde 1920). El obstáculo principal a la aprobación de la candidatura de Kantor consistió en que él no hablaba los idiomas en que se daban las clases en la ELI. Pero Codovilla logró convencer a Togliatti (y a la administración de la escuela), de que Kantor -nacido en Rusia y hablaba yiddish-, podía superar el curso en alemán. De alguna manera, para Kantor el viaje a la ELI fue una forma de volver a sus raíces.

El Comité Ejecutivo de la IC entendía que los jóvenes Partidos Comunistas latinoamericanos no disponían de militantes suficientes que dominaran los idiomas indicados para la aceptación en la escuela. ${ }^{18}$ El español se convirtió en idioma de instrucción sólo en los años 30, cuando en ella fue creado el sector "L" para la capacitación de los cuadros comunistas españoles y latinoamericanos.

El secretario del Secretariado Sudamericano, José F. Penelón, y el secretario general del PCA, Pedro Romo, aprobaron esta elección, y el delegado de la Federación de las Junventudes Comunistas de Argentina, Kantor, fue a Moscú como delegado de la FJCA a la sesión plenaria del CE de la Internacional Comunista de las Juventudes, quedándose ahí para estudiar en la ELI ${ }^{19}$.

\footnotetext{
${ }^{16}$ Ricardo García Treviño. "El regreso de Evelio Vadillo”. Nexos, México (1 de diciembre de 1990). http://www.nexos.com.mx/?p=6041

17 "Carta de Ercoli (P. Togliatti) al SSAIC". Moscú, 11 de junio de 1926. RGASPI. F. 503, inv.1, exp. 7, f. 2.

18 "Carta de Ercoli (P. Togliatti) al Secretariado del Partido Comunista de Argentina”. Moscú, 6 de julio de 1926. RGASPI. F. 495, inv. 134, exp.77, f. 144.

19 "Carta de Pedro Romo, secretario general del PCA, a los camaradas del Comité Ejecutivo de la Internacional Comunista". Buenos Aires, 23 de julio de 1926. RGASPI. F. 495, inv. 134, exp. 78, f. 100; "Expediente personal de Antonio Kantor". RGASPI. F. 495, inv 190, exp.35; "Expedientes del transfer al PCR (b)". RGASPI. F. 17, inv. 98, exp. 830, fs. 1-4.
} 
El Secretariado de los países hispanoparlantes discutió dos veces la candidatura de Kantor, votándo finalmente en contra de la posibilidad de que este trabajara en el aparato del CE de la ICJ, no considerándolo apto para ese tipo de colaboraciones. No obstante, le permitió estudiar en la ELI a condición de que en dos o tres meses, aprendiera el idioma alemán. En noviembre de 1926, Kantor fue trasladado al PCR (b), mientras estudiara en la escuela. Tras terminar sus estudios, a finales de 1928, el argentino regresó para formar parte del CC del PC de Argentina ${ }^{20}$. La carrera de este "precursor latinoamericano", después de su retorno a Buenos Aires, representó para la Comintern el caso idóneo de formación de militantes: adiestrar a los jóvenes comunistas en Moscú para que luego sirvieran de cuadros partidarios en sus países y se convirtieran en los dirigentes de sus partidos.

La siguiente convocatoria abarcó a más militantes del subcontinente, y un primer grupo de futuros cursantes latinoamericanos llegó a Moscú en el verano/otoño del 1927. Se trató, esta vez, de ocho "verdaderos" latinoamericanos, de pura cepa, que inicialmente fueron a Moscú para participar en los festejos del X aniversario de la Revolución de Octubre. Indudablemente, la mayor atención de la que gozó América Latina desde el VI Congreso de la Comintern (julio/agosto de 1928), contribuyó a que fueran elegidos para seguir un cursillo en la ELI. Se trataba del peruano Eudocio Ravinez; el chileno Rufino Rosas Sánchez; el ecuatoriano Ricardo Paredes; el argentino Solomón Elguer ("Vidal"); el colombiano Guillermo Hernández Rodríguez (“Guillén”); la venezolana Cármen Fortul Briceño ("Cácerez"); el brasileño Heitor Ferreira Lima ("Silva”) y el uruguayo Cárlos Imaz ("Loris"). Junto con ellos, fue aceptado el comunista estadounidense John Zack ("Kass"), quien posteriormente desempeño un importante rol en la creación de los Partidos Comunistas de Colombia y Venezuela ${ }^{21}$.

El secretario del CEIC, el suizo Jules Humbert-Droz, subrayó la necesidad de "aplicar un esfuerzo especial en cuanto a América Latina, donde hay muchas posibilidades para desarrollar nuestro movimiento pero existe mucha confusión ideológica. Cuba, Colombia, Ecuador, Brasil, Chile, México, Paraguay son de importancia especial""22. En el año 1928, el grupo de latinoamericanos en la ELI se engrosó con el colombiano Diego Mejía ("Rodríguez"), el mexicano Xavier Guerrero ("Pérez"), el uruguayo Gilberto Chiappapietra ("Aguilar") y, un año más tarde, con los argentinos Alfredo Quevedo (“Juárez") y José N. Cosme Caggiano ("Rúiz”), y los brasileños José Lago Molares ("González") y Grigorii Berezin ("Grishin") 23. Cabe notar que "Grishin" - a pesar de ser miembro del PCB y de su Comité Central- no era de nacionalidad brasileña. Había nacido en el Imperio Ruso, ingresó en el Partido Comunista Ruso durante la guerra civil, pero después emigró a Brasil donde se hizo uno de los organizadores del PCB. En aquel entonces, este tipo de militantes, todavía podía ser admitido en la ELI, sin embargo, a

\footnotetext{
20 “Expediente personal de Antonio Kantor". RGASPI. F. 495, inv. 190, exp. 35.

${ }^{21}$ Heitor Ferreira Lima. Caminhos Percorridos. Memoria de militância (S.1, 1982) 81.

22 "Carta del Secretariado Latino del CEIC a la Universidad Oriental”. Moscú, 26 de junio de 1928. RGASPI. F. 495, inv. 32, exp.35, f. 209.

23 “Listados de los estudiantes de la ELI de 1926 a 1931”. RGASPI. F. 531, inv. 1, exp.31, fs. 7 - 33.
} 
inicios de la década del 30, la Comintern prohibió enviar como candidatos a militantes que habían emigrado de la URSS después de la revolución bolchevique.

Aprovechando "el descubrimiento de América Latina" tras el VI Congreso de la IC, el Secretariado Sudamericano del CEIC exigió al cuerpo superior de la Internacional, prestar más atención a la capacitación de cuadros para los partidos comunistas de la región. El SSAIC, al detectar que el crecimiento de los partidos comunistas se estancaba y que los intentos de ganar alguna influencia política no daban frutos (a pesar de que el movimiento revolucionario latinoamericano, en general, todavía estaba en auge), propuso subir la cuota de estudiantes latinoamericanos en la ELI a 20 personas ${ }^{24}$.

El CEIC no quiso aceptar la iniciativa, sin embargo encontró una 'solución solomónica": a partir del año 1929, la KUTV inauguró cursos en español para 60 representantes de los partidos de América Latina. Al SSAIC, Moscú le encomendó elegir dos candidatos de cada partido de los siguientes países: Argentina, Brasil, Chile, Paraguay, y uno de Uruguay. Al Partido Comunista mexicano se le encargó encontrar la gente apropiada en Cuba (2), Colombia (3), Guatemala (1), Venezuela (1), Honduras (1), Nicaragua (1) y El Salvador (1). El mismo PCM recibió el derecho de enviar tres candidatos a la KUTV. El PC de Ecuador pudo elegir una candidatura por su propia cuenta. El boliviano Tristán Maroff, que vivía en aquel entonces en México y participaba en las actividades de la Liga Antimperialista de las Américas, recibió una invitación personal (de hecho, la invitación fue organizada gracias a las gestiones del PCM). Sin embargo, esta cuota nunca fue mayor al $50 \%$.

De manera cierta son conocidos sólo once estudiantes de América Latina en la KUTV: el paraguayo Sergio Báez ("Lapin”), el argentino Humberto Solaro ("Olmedov"), los ecuatorianos José Álvaro ("Gabatti"), Gustavo Salgado, José Moscoso ("Dumol”), Felicio Bruno, Junqueiro (“Gayón”), los brasileños Cárlos Augusto da Silva ("Lunin”) y Russildo Magallães ("Lesov"), el uruguayo Bruno Bonilla (“Akimov”), el salvadoreño Aquilino Salinas Martínez ("Cortés"). Según los datos disponibles, un uruguayo (militante del PCU) Shenkman, también fue enviado a la KUTV, sin embargo, no hay certeza si logró graduarse. Cabe notar que María Fortus, que trabajaba en la Sección Latinoamericana de la ISR, se había graduado de la KUTV, sin embargo, no era representante de ningún partido latinoamericano, sino que cursó como ciudadana soviética, realizando también funciones de secretaria de la Universidad. El dirigente del PCE, Ricardo Paredes, confirmaba la presencia en la KUTV de solo cuatro paisanos suyos: "Cuatro camaradas, miembros de P. S., recibieron las becas para estudiar en la Universidad [Comunista] de [Trabajadores del] Oriente. Estos camaradas ya se fueron de Ecuador y están asistiendo a las clases en la universidad" 25 .

Las decisiones aprobadas correspondieron a los planes emanados del CEIC después del VI Congreso, y en el cual el trabajo en los países coloniales y semi-coloniales, fue

\footnotetext{
24 “Carta del Secretariado Sudamericano (Garlandi) a la Comisión Política del CEIC”. Moscú, 25 de enero de 1930. RGASPI. F. 495, inv. 79, exp.112, f. 31.

25 “Telegrama de R. Paredes a E. Terán”. S.f.. RGASPI. F.495, inv. 67, exp. 1, f. 42; “Carta del CC del PSE, sección del III Intenacional Comunista al Secretario General de la Sección Latina del Comintern”. Quito, 20 de julio de 1929. RGASPI. F. 495, inv. 67, exp. 8, f. 54.
} 
reconocido como una de las actividades prioritarias. El proyecto elaborado por el Secretariado Oriental del CEIC, estipulaba la ampliación de las accciones de la KUTV, además del cambio de su nombre por el de Universidad Comunista de los Trabajadores de los Países Coloniales y Semicoloniales de Oriente I.V. Stalin. La Comintern acordó dividir el trabajo de instrucción por regiones formando, con este objeto, once sectores: japonéscoreano (150-200 personas), chino (250-300 personas), centroasiático (Mongolia, Tuvá, Sinkiang y Tíbet), Océano Pacífico (Australia, Nueva Zelanda, Hawái, Fiyi, Samoa, Nueva Caledonia), indo-malayo (Filipinas, Archipiélago Malayo, Indochina, Siam), índio (250300 personas), afgano-pérsico, túrco, árabe (100 personas), negro (150 personas), latinoamericano (100 personas). Además, el sector soviético-oriental debía contar con 400 personas. ${ }^{26}$ Según los autores del proyecto, se debía tomar en cuenta la falta de traducciones de obras marxistas básicas a los idiomas de los pueblos coloniales, junto con la ausencia casi completa de instructores que dominaran estos idiomas. Consecuentemente, propusieron extender el período de estudios en la Universidad Comunista hasta cuatro años, con el fin de asegurar la asimilación eficiente de la teoría marxista-leninista. Para capacitar los cuadros de los países que se encontraban en situación prerrevolucionaria, como China o India, y formar a los funcionarios de los Partidos Comunistas de los países subdesarrollados, proponían organizar cursos de dos años. Mientras, los estudiantes enviados desde los países que se encontraban en situación revolucionaria, podrían ser admitidos a los cursos de plazo breve (nueve meses). Para algunos partidos, donde la escasez de cuadros dirigentes era muy evidente, el período de estudios podía ser disminuido aún más. La tarea principal, según los autores del proyecto, de cualquier modo sería cumplida: el prestigio del partido aumentaba con la presencia en el mismo de cuadros capacitados en el centro del movimiento comunista internacional. Se suponía que la falta de los conocimientos teóricos básicos, podía ser compensada con la preparación previa in situ, durante el trabajo práctico, más estudios personales.

Varios dirigentes comunistas estuvieron de acuerdo con este enfoque. Según el ecuatoriano R. Paredes, los estudiantes enviados por su partido a KUTV, "debieran permanecer únicamente un año, pues necesitamos ante todo militantes activos, aunque no tengan una profunda preparación, la que adquirirán con el tiempo"27.

A primera vista, resulta sorprendente que la KUTV, la escuela de cuadros creada en 1921 para estudiantes procedentes de las repúblicas soviéticas orientales y de los países coloniales del Próximo, Mediano y Lejano Oriente (Japón incluido), acogiera estudiantes de América Latina. El hecho se explica, tal vez, por el estatus que la Comintern atribuyó, sobre todo después de su VI Congreso, a los países del subcontinente latinoamericano: el de "países semi-coloniales". En la misma lógica, también los comunistas negros de EE.UU.

\footnotetext{
${ }^{26}$ Sobre la KUTV véanse Branko Lazitch. “Les écoles de cadres du Comintern”. En: Jacques Freymond. Contributions á l'histoire du Comintern (Genéve: Ed. Librarie Droz, 1965) 233-257.

27 “Carta del CC del PSE, sección de la Internacional Comunista al Secretario General de la Sección Latina de la Internacional Comunista". Quito, 10 de agosto de 1929. RGASPI. F. 495, inv. 67, exp.8, f. 57 dorso; “Carta del CC del PSE, sección del III Internacional Comunista al Secretario General de la Sección Latina del Comintern”. Quito, 20 de julio de 1929. RGASPI. F. 495, inv. 67, exp. 8, f. 54.
} 
(considerados como "nación oprimida") y los comunistas de África austral, fueron enviados a la $\mathrm{KUTV}^{28}$.

Sin embargo, los ambiciosos planes del Secretariado Oriental no fueron realizados. Tampoco fueron aprovechadas las posibilidades que se habían presentado para los comunistas latinoamericanos en virtud de las decisiones tomadas por la Comintern en los años 1928-1929: durante todo el período de funcionamiento del programa citado, los partidos latinoamericanos no consiguieron cubrir la cuota asignada a ellos. Es muy ilustrativo el hecho de que durante todo el período de funcionamiento de la ELI, varios partidos no llegaron a completar la cuota anual asignada a partir del año 1931 (época de aumento de los estudiantes en la escuela). Por ejemplo, al Partido Comunista de Bolivia (PCB) se le exigía enviar dos estudiantes (incluso un indígena), y al Partido Comunista de Chile (PCCh) cuatro (incluyendo un indígena), lo cual jamás fue realizado ${ }^{29}$.

Los dirigentes del PCM escribían al SSAIC que, a pesar de que los comunistas mexicanos no habían cubierto la cuota de estudiantes para la ELI y la KUTV asignada en 1929, para el año siguiente el plan consideraba un aumentado, lo que perjudicaba al partido. El Secretario General del PCM, Hernán Laborde, exigió que el SSAIC aclarara las contradicciones existentes entre los órganos dirigentes de la Comintern, pues pensaba que una de las causas de tales equivocaciones, era la "falta de atención a éste asunto por parte del Secretariado Sudamericano"30.

La imposibilidad de cubrir las cuotas fue causada por varias razones. La primera tenía que ver con la escasez de militantes comunistas y las dificultades para seleccionar aspirantes para estudios en Moscú que correspondieran a los criterios estrictos propuestos por la Comintern. La segunda era la situación de pobreza de la mayoría de los partidos latinoamericanos y sus muchos problemas financieros. Por fin, la fundación de una escuela comunista continental adjunta al SSAIC, hacía irracional el envio de mucha gente a Moscú. No sorprende, en consecuencia, que el grupo comunista venezolano en Panamá, al recibir invitación para enviar dos candidatos a la ELI y tres para la KUTV, escogiera a uno sólo, H. Balbino Acosta ${ }^{31}$, sin que haya seguridad de que fuera, efectivamente, a la URSS.

En la Comintern se creía que la capacitación militar era un elemento sustancial del adiestramiento de cara a la imminente "revolución mundial". La rectora de la KUNMZ, Maria Yakovlevna Frumkina, al evaluar el proceso educativo en la Universidad, mencionaba que todos los alumnos que habían pasado la capacitación ahí, eran reservas especiales del Ejército Rojo y de la Comintern, de modo que tenían que estar listos para

\footnotetext{
${ }^{28}$ Ejemplos de los estudiantes negros de EE.UU. en la KUTV son: Otto Hall (“Carl Jones”), Roy Mahoney ("Farmer"), William Patterson, George Padmore, Harold Williams, Maude White, Herbert Newton, Marie Houston, Vaughan Mise y Aurora Wilson.

29 "Carta del Secretariado Latinoamericano del CEIC al Buró Sudamericano del CEIC”. Moscú, junio de 1931. RGASPI. F. 495, inv. 79, exp.153, f. 54.

30 “Carta del Secretario General del PCM, H. Laborde, al Secretariado Sudamericano”. México, 15 de agosto de 1930. RGASPI. F. 495, inv. 108, exp.131, f. 84.

31 “Carta de H. Balbino Acosta a G. Machado". Panamá, 17 de julio de 1930. RGASPI. F. 495, inv. 116, exp.6, f.18.
} 
entrar en funciones en cualquier momento ${ }^{32}$. Docenas de comunistas extranjeros fueron enviados por sus partidos a estudiar en las instituciones educativas militares de la URSS. La más conocida era la Academía Militar Mijail V. Frunze, que aceptaba como cadetes (aparte del contingente básicamente soviético), en primer lugar, a militantes de partidos comunistas ilegales de los países capitalistas, de Bulgaria (a partir del año 1924), Alemania (a partir de 1933) y de España (a partir de 1937) ${ }^{33}$.

Sin embargo, los latinoamericanos fueron notable excepción en el proceso de adiestramiento militar. De acuerdo a los datos disponibles, sólo un latinoamericano estudió en la Academía Militar. Alumno de la ELI, del 11 de julio de 1931 a 1933, se tratató del cubano Ramón Nikolau Gonzáles ("Justo Ríos"). No logró terminar el curso militar, porque poco después de empezar sus estudios, el Partido Comunista de Cuba solicitó su regreso urgente al país en vistas a la revolución de agosto de 1933, contra la dictadura de Gerardo Machado. Bajo el seudónimo "Esteban”, se incorporó al Secretariado y al Buró Político del PCC (17.12.1933) y fue designado encargado del trabajo militar del partido y dirigente del Ejército Libertador (1934). Más tarde, encabezó el reclutamiento de los voluntarios cubanos a las Brigadas Internacionales con ocasión de la Guerra Civil en España ${ }^{34}$.

Durante la preparación del levantamiento brasileño de la Aliança Nacional Libertadora (ANL), en 1935, se creó un grupo especial para estudiar la experiencia de organización partidaria, militar y soviética de China. Los egresados brasileños de la ELI, Silo de Meireles y José M. De Sousa, y el cubano Pinjos Meshkop (“Cristóbal Ramón”), formaron parte de este grupo. En la escuela del Departamento de Comunicación Internacional del CEIC, estuvieron los italianos Bartolo Maroni (militante del PCA) y Amlezo Locatelli; y el estadounidense Victor Allan Barron. Los dos últimos participaron en las actividades de la ANL en Brasil, en 1935, mientras que Maroni fue combatiente en las Brigadas Internacionales en España. Un papel importante en la preparación de la insurgencia en Brasil, lo desempeñó la egresada de la Escuela Superior del Aire, la alemana Olga Benario ${ }^{35}$, esposa del "Caballero de Esperanza", Luis Carlos Prestes. La brasileña Clotilde Prestes, hermana del Luis Carlos Prestes, estudió tres años en la escuela de radio del CEIC. Según los expedientes sobre los voluntarios mexicanos en la Guerra Civil en España, el mexicano David Serrano Andonegui ("Justo"), también recibió educación militar en Moscú. Sin embargo, a diferencia del caso de R.Nicolau, no hay total certeza sobre el hecho.

Los cursos de la ELI debían brindar contenidos de capacitación altamente útiles para los dirigentes comunistas, pues se debía reforzar sus conocimientos en la teoría del

\footnotetext{
32 “Carta de M. Frumkina a Pyatnitskii, Manuilskii, Knorin, Krayevskii”. Moscú, 12 de febrero de 1935. RGASPI. F. 495, inv. 20, exp. 862, f. 7.

${ }^{33}$ Había, por lo menos, 35 alumnos españoles, entre ellos: Enrique Lister Forján (por cierto, en 1927 militó en el PC de Cuba hasta su expulsión de la isla por el gobierno de Gerardo Machado), Juan Modesto, Valentín González ("El Campesino") y Manuel Tagüeña Lacorte.

34 “Expediente personal Ramón Nicolau”. RGASPI. F. 495, inv. 230, exp. 15. Véase también: El militante comunista. La Habana (Agosto de 1985): 160.

${ }^{35}$ Véase Lazar Jeifets, Víctor Jeifets, Peter Huber. La Internacional Comunista y América Latina, 1991-1943. Diccionario biográfico (Ginebra, 2004); Lazar Jeifets y Víctor Jeifets. América Latina en la Internacional Comunista, 1919-1943. Diccionario Biográfico (Santiago de Chile: Ariadna Ediciones, 2015).
} 
marxismo-leninismo y en la experiencia de lucha de los partidos de otros países. En los marcos del curso se daban clases de ecconomía mundial, de los problemas de estrategia y táctica de la Comintern, de experiencia organizativa y política del Partido Comunista Ruso /bolchevique/ en el área de preparación y ejecución de la revolución proletaria triunfante, así como en la práctica de la dictadura de proletariado en beneficio de los trabajadores de la URSS y en provecho de la victoria del "trabajo sobre el capital" en todo el mundo. Los alumnos de la ELI (al igual que varios estudiantes de la KUTV), tenían que tomar parte en la resolución de asuntos prácticos de las actividades de los Partidos Comunistas y de la Comintern, en general, asistiendo a las reuniones de varios sus Secretariados y de la Internacional Sindical Roja, o trabajando como asesores de ambas organizaciones. Además, participaban en discusiones sobre tal o cual problema, en plena sintonía con los debates dentro de la III Internacional ${ }^{36}$.

Un problema agudo en las escuelas cominternistas, fue la falta de profesores, por lo menos así era el caso de los instructores que tenían que dar clases a los estudiantes procedentes de los países romanos (Mediterráneo) y latinoamericanos. En la Comintern se podían contar con los dedos de la mano los especialistas en asuntos de América Latina. Además, algunos de ellos casi no hablaban español, lo que complicaba enormemente sus contactos con los estudiantes de esta región.

De a paoco, esta situación empezó a cambiar a principios de los años 1930, tras la reorganización del aparato del CEIC, cuando, bajo Georgi Borisovich Skalov ("Sinani") que desempeñaba el cargo de dirigente provisional del Secretariado Latinoamericano- se ocupó de formar un grupo soviético de estudios marxistas de temas latinoamericanos. El mismo Skalov, nombrado subsecretario del Secretariado Latinoamericano del CEIC, dió clases en la EIL encabezando, al mismo tiempo, la cátedra de América del Sur y del Centro en el Instituto de Estudios Orientales N. Narimanov. En aquel tiempo, los ex-funcionarios del SSAIC, Mark S. Jaskin ("Maurice") y Nadezhda Yakovlevna Tulchinskaia ("Inés"), regresaron a Moscú, desempeñándose, simultáneamente, en el aparato del CEIC y de la Internacional Sindical Roja, y como docentes en la ELI. Al poco tiempo, a este equipo se unió Yulii Isaakovich Rozovskii ("Julio Gómez"), militante y dirigente del Partido Comunista de México (de orígen ruso judío) deportado de aquel país durante una hola de 'cacería de extranjeros rojos' desatada por el gobierno de Pascual Ortiz Rubio. El representante de promoción del Instituto de Profesores Rojos (IPR), Vladimir Mijailovich Miroshevskii, fue nombrado jefe del sector del Secretariado Latinoamericano. Este, junto a Anna Markovna Aleksandrova-Itkina que, a la sazón, había regresado de Buenos Aires donde había trabajado en la representación comercial de la URSS, empezaron a participar en estas labores, turnándose para encabezar el grupo latinoamericano del sector "L" en la ELI. La forma de organizar los estudios por grupo, a juicio de los dirigentes de la ELI, permitía analizar y estudiar de manera profunda los problemas de la región (posteriormente, en 1936, el sector "L" fue subdividido en seis grupos: cinco grupos hispano-portuguéses y

\footnotetext{
${ }^{36}$ Véase, para ejemplo, "Reunión del Grupo Nacional Latinoamericano, realizada el 12/3/30". RGASPI. F. 531, inv. 1, exp. 182a, fs.1-4.
} 
un grupo latinoamericano ${ }^{37}$ ). Algún tiempo el sector fue dirigido por Nikolai Nikolaevich Mayorsky y Stepan Efimovich Schukin (“Lorenz"), éste último, encargado, dentro del Secretariado Latinoamericano, de mantener los contactos con el grupo latinoamericano de la ELI.

El suizo Edgar Woog (“Alfred Stirner”), quien era el experto más apto de la Comintern en los problemas de la izquierda latinoamericana (había militado algun tiempo en la Federación de Juventudes Comunistas de México y en el PCM, y era miembro del CEIC por América Latina) ocupó el puesto de catedrático de la cátedra de organización comunista. El grupo de docentes del sector "L" estuvo también integrado por Grigorii Moiseevich Yakobson (daba clases, a su vez, en el IPR y en la KUTV) e I.G. Markov (Instituto Internacional Agrario). Algunos ex militantes de la izquierda latinoamericana de orígen ruso-judío o polaco-judío, al regresar a la patria, fácilmente encontraron sitio en la ELI: Froim Gershovich Weiner (miembro del PC y del Socorro Rojo en Argentina, hasta 1930) fue subjefe del sector "L". El puesto de secretario del sector, fue ocupado por Juan Aronovich Jazán (militante en el PC de Cuba hasta 1931-1932), mientras que Julia CoralYaselmán (militante del PCA hasta 1927), fue docente de idiomas extranjeros ${ }^{38}$. Las funciones de traductores en la ELI las ejercían los docentes y funcionarios de otras instituciones. Casi nadie de ellos era lingüista profesional, habiendo aprendido idiomas durante el tiempo de emigración ${ }^{39}$. Posteriormente, al cuerpo de profesores del sector "L" llegaron el chino Van Min (era la cabeza del Secretariado Latinoamericano), el ruso de orígen polaco Stanislav Pestkovsky ("Ortega") 40 , el italiano David Maggione ("Marcucci") y el búlgaro Jorda Terziev (Janko Atanasov). A excepción de Terziev, todo el grupo tenía vastos conocimientos sobre América Latina lo que facilitaba la incorporación de los alumnos al proceso de capacitación. El grupo de profesores del sector latinoamericano era visiblemente mejor comparado con el sector español, donde apenas 2 de los 9 profesores conocían bien la situación en España ${ }^{41}$.

En 1935 Georgi B. Skalov fue una de las primeras víctimas de la oleada de represalias stalinistas en la Comintern. Después de su arresto y encarcelamiento, el colectivo de especialistas en asuntos de América Latina qu él había formado, se desintegró paulatinamente. El mismo sector "L" sufrió varias remociones de docentes. Los dirigentes del sector evaluaron a muchos docentes como insatisfactorios. Sus conclusiones se basaban en dos razónes: la falta de conocimientos sobre países latinoamericanos (lo que no era tan cierto, como ya hemos expuesto) y la imposibilidad de concentrarse en el trabajo en la ELI

\footnotetext{
37 "Estructura del sector "L". Oficio del jefe del sector "L", L. Mikhailov". Moscú, 19 de febrero de 1936. RGASPI. F. 531, inv. 1, exp.185, f. 16.

${ }^{38}$ Para más detalles, véase: Lazar Jeifets, Víctor Jeifets, Peter Huber. La Internacional Comunista y América Latina, 1991-1943. Diccionario biográfico (Ginebra, 2004); Lazar Jeifets y Víctor Jeifets. América Latina en la Internacional Comunista, 1919-1943. Diccionario Biográfico (Santiago de Chile: Ariadna Ediciones, 2015). 39 "Estructura del sector "L". Oficio del jefe del sector "L", L. Mikhailov". Moscú, 19 de febrero de 1936. RGASPI. F. 531, inv. 1, exp.185, f. 16. Era el caso, por ejemplo, de Olga Moiseevna Malamud nacida en Ukrania. Estuvo varios años en exilio en Argentina donde aprendió el idioma español.

${ }^{40}$ Tenía vasta experiencia revolucionaria y durante algun tiempo era el Enviado Plenipotenciario de la URSS en México desempeñando al mismo tiempo el cargo del representante de la Comintern en éste país.

41 "Estructura del sector "L". Oficio del jefe del sector "L", L. Mikhailov". Moscú, 19 de febrero de 1936. RGASPI. F. 531, inv. 1, exp.185, f. 17.
} 
por tener que compartir su tiempo con ocupaciones en otras instituciones cominternistas. Como sea, la escasez de cuadros docentes y la rotación permanente del personal, perjudicaron de manera ostensible el trabajo de la escuela.

En el proceso de envío de candidatos a las instituciones educativas de la Comintern, los funcionarios del CEIC, a pesar de saber de que los partidos latinoamericanos y el SSAIC (ni tampoco el Buró del Caribe, fundado más tarde) no tenían la posibilidad de costear los viajes, no transferían los recursos a tiempo y, a menudo, ni siquiera informaban de la fecha de partida de los futuros alumnos hacia la URSS.

El sistema multinivel de distribución de información y financiamiento de las secciones nacionales por parte de los órganos supremos de la Comintern, se convertía en el obstáculo más serio y, a veces, invencible, para asegurar el traslado de los seleccionados a estudios en las escuelas de cuadros. Ejemplo ilustrativo fue la situación de los estudiantes ecuatorianos: Ricardo Paredes concertó en Moscú la entrega de 800 dólares a la sección ecuatoriana para finales de 1928 y los subsidios mensuales, a partir del año 1929. Cuando el partido recibió estos 800 dólares, en el CC del PCE consideraron que se trataba del dinero para cuatro becarios de la KUTV. Dentro de una semana llegó el telegrama desde Berlin que decía: "Reciba los necesario para el viaje de los estudiantes a través del tío en Buenos Aires". Al creer que "el tío" era Victorio Codovilla (el secretario del SSAIC), el PCE se dirigió al Secretariado Sudamericano preguntando si éste había recibido el dinero referido. Sin embargo, Codovilla contestó que no sabía nada de eso ${ }^{42}$. Otro caso fue este: el Secretariado Latinoamericano del CEIC comunicó al clandestino Partido Comunista de México sobre la necesidad de enviar siete personas para las escuelas de cuadros, con la aclaración de que las instrucciones pormenorizadas debían recibirlas desde el SSAIC. En junio de 1930, al no recibir las instrucciones - la gente tenía que llegar a Moscú en agosto del mismo año-, el CC del PCM solicitó al CCE del Partido Comunista de los EE.UU. aclarar la situación y otorgar los recursos necesarios (1.050 dólares) para el viaje de los estudiantes mexicanos ${ }^{43}$, sin embargo, ya era demasiado tarde para enviar a los siete alumnos.

Además, la información sobre la cantidad de plazas asignadas a América Latina y la distribución de las mismas por los países, también tardaba mucho. En casi todas las cartas del SSAIC a Moscú, se notaba la misma inquietud: "no tenemos información sobre la cantidad de plazas reservadas para América Latina ni sobre la cantidad de plazas reservadas para cada país ni sobre las fechas de partida de los estudiantes. Esperamos recibir pronto los mensajes exactos, y si ustedes todavía no lo han hecho en el momento de recibir la presente carta, les pedimos hacerlo inmediatamente" ${ }^{44}$. A menudo los candidatos llegaban a Moscú y vivían allí en espera de la convocatoria, sin tener recursos financieros suficientes.

El aparato del CEIC compartía el punto de vista con los latinoamericanos: no estaba contento con la organización de la admisión de los estudiantes de esta región. El

\footnotetext{
42 "Carta del CC del PSE, sección de la Internacional Comunista al Secretario General de la Sección Latina de la Internacional Comunista”. Quito, 10 de agosto de 1929. RGASPI. F. 495, inv. 67, exp.8, f. 57 dorso.

43 "Carta del Secretario General del PCM, H. Laborde, al Secretariado Sudamericano de la Comintern". México, 17 de junio de 1930. RGASPI. F. 495, inv. 108, exp. 131, f. 76.

44 "Carta de Codovilla al Secretariado Latinoamericano de la Comintern". Buenos Aires, 5 de septiembre de 1928. RGASPI. F. 503, inv. 1, exp. 19, f. 38.
} 
Secretariado Latinoamericano del CEIC hacía constar que los estudiantes de América Latina tardaban en llegar para el inicio de los estudios, lo que dificultaba el desarrollo normal del proceso educativo e implicaba la prolongación del plazo su estadía. Los funcionarios de la Comintern señalaban que los partidos, a menudo, incumplían los requerimientos de composición social de los estudiantes, insistiendo en que, en primer lugar, era necesario enviar a obreros de empresas e industrias principales. Se trataba de mineros (Chile, Perú, Bolivia, Brasil), petroleros (Perú, Argentina), trabajadores de frigoríficos (Argentina, Uruguay), obreros portuarios (Argentina, Uruguay, Brasil, Chile, Perú), obreros de la industria textil, ferroviarios, trabajadores del sector agrario (para todos los países).

Tomando en cuenta la gran cantidad de indígenas y negros en el cuerpo étnico sudamericano, los dirigentes del CEIC consideraron necesario la presencia en Moscú de comunistas que pertenecieran a estos grupos étnicos y raciales. De igual forma, exigía que comisionaran a comunistas jóvenes y mujeres obreras, creyendo que su papel en el movimiento revolucionario estaba constantemente. $\mathrm{Si}$, en el caso de los jóvenes, esta demanda era relativamente fácil de satisfacer (el porcentaje de jóvenes en los partidos era alto), en lo que concernía a la presencia femenina, el asunto era más complicado. Desde inicios de los años 30, el CEIC aumentó la cuota para latinoamericanos, empezando a controlar estrictamente la proporción de hombres y mujeres y la presencia de indígenas (los Partidos Comunistas de Brasil, Chile, Bolivia, Perú y Ecuador, tenían que delegar estudiantes indígenas o negros) entre los candidatos ${ }^{45}$. Empero, los esfuerzos por contar con mujeres a las escuelas de cuadros en Moscú, no dieron frutos. Según nuestros datos, durante todo el tiempo de existencia de la ELI, sólo estudiaron ahí las siguientes mujeres: la venezolana Cármen Fortul Briceño ("Cáceres", 1928), las cubanas Cármen Grandío Leal (“Alejandra", 1937) y Bela Rosa Acosta Fernández ("Olga”, 1937), brasileña Jenni Gleizer (“Anita Rodríguez", 1937) y la colombiana Laura Paz (1937). Además, la brasileña Clotilde Prestes estudió en una escuela de radio del CEIC (1934-1936) y la argentina Raquel Levensón se graduó de una escuela de cuadros de la Comintern en 1943, es decir, después del cierre oficial de la ELI.

En general, el proceso de selección de candidatos en las secciones nacionales, a menudo estuvo acompañado de fuertes conflictos intrapartidarios pues muchos estaban seguros de que la capacitación en las escuelas de la Comintern y la experiencia de trabajo en el aparato del CEIC, abriría a los egresados un camino directo a los cargos más altos en sus respectivos partidos. Además, la posibilidad de pasar varios años en la patria de los bolcheviques, en la Meca comunista, era el sueño de muchos militantes que querían ver con sus propios ojos 'el milagro soviético'.

Así, durante la crisis al interior del Partido Comunista del Paraguay (PCP), Lucas Ibarrola, destituido de su cargo de dirigente del partido tras injerencia directa del argentino Victorio Codovilla, consideraba que el envio del hijo del nuevo Secretario General del partido (M. Báez) a Moscú, era capricho personal del Secretario del SSAIC y no la decisión tomada por el partido. El ex líder del partido acusó al hijo Báez de falta del credo

45 "Carta del Secretariado Latinoamericano del CEIC al Buró Sudamericano del CEIC". Moscú, junio de 1931. RGASPI. F. 495, inv. 79, exp.153, f. 54. 
comunista, al mantener relaciones cercanas con la juventud burguesa y de desprecio de los pobres (en sus cartas nunca puso su nombre y sólo logramos recuperar este dato de otros documentos $)^{46}$.

Las dificultades financieras y de organización que acompañaban las convocatorias, eran motivo para pensar en la creación de un sistema de educación partidaria en América Latina, sin necesidad de ir a la URSS. Luego de la primera Conferencia Comunista Latinoamericana (Buenos Aires, 1929), el asunto se hizo especialmente claro. Al reconocer la creciente importancia de América Latina para el movimiento revolucionario mundial, el Secretariado Político del CEIC decidió intensificar el trabajo de la IC en el continente. Moscú apoyó la fundación en América Latina de un centro dirigente y coordinador, siendo una de sus prioridades la formación de una escuela partidaria en el continente ${ }^{47}$.

La izquierda latinoamericana tenía su propia experiencia de enseñanza de militantes obreros, la que había tenido lugar, por ejemplo, durante la lucha estudiantil por la reforma universitaria. En varios países de la región, el movimiento estudiantil mantenía estrechas relaciones con los sindicatos obreros, aspecto que el escritor y pensador peruano José Carlos Mariátegui, ponderó como uno de los testimonios de renovación profunda de América Latina. Esta unión dió origen al concepto de "Universidades Populares" en las que los intelectuales jóvenes, junto con los obreros, estudiaban las ideas progresistas y aplicaban sus conocimientos por el bien del proletariado, proporcionándole la "gestión intelectual". Es simbólico que las universidades creadas en Perú y en Cuba, recibieron los nombres del periodista M. González Prada y del prócer de la Independencia de Cuba, José $\operatorname{Martí}^{48}$. Estas instituciones docentes no eran precisamente escuelas de capacitación de los funcionarios comunistas. Sin embargo, en ellas varios personajes prominentes del movimiento obrero latinoamericano comulgaron con la teoría revolucionaria ${ }^{49}$. Los profesores de las Universidades Populares tomaron parte activa en la creación del PC de Cuba, del Partido Comunista del Perú (PCP) y de la Alianza Popular Revolucionaria Americana (APRA), además de militar en varios otros Partidos Comunistas. Algunas organizaciones comunistas trataron de crear sus propias escuelas nacionales para sus miembros. El Partido Comunista del Ecuador (PCE), fue pionero en este proceso al organizar en Quito la Escuela Leninista de Educación Marxista-Leninista y Economía Nacional. La tarea principal de esta Escuela consistía en capacitar a los activistas del PCE "para la lucha de hoy y la construcción comunista de mañana",50.

\footnotetext{
46 "Carta de Lucas E. Ibarrola a la Comintern”. 12 de abril de 1929. RGASPI. F. 495, inv. 117, exp. 6, f. 36 ; “Carta de L. E. Ibarrola al Secretariado de la Comintern”. Asunción, enero de 1929. RGASPI. F.495, inv. 117, exp. 6, fs. 25-27.

47 “Sugerencias del Secretariado Latinoamericano respecto al trabajo en América Latina”. Moscú, 2 de agosto de 1929. RGASPI. F. 495, inv. 79, exp. 66, fs. 37-38.

48 José Carlos Mariátegui. Siete ensayos de interpretación de la realidad peruana (Moscú: Izdatelstvo Inostrannoi literatury, 1963) 159-160. Citado por: Yuri P. Gavrikov. Conciencia del Perú (M.: Politizdat, 1987) 21. La Universidad Popular González Prada fue creada por Víctor Raúl Haya de la Torre en Lima en el año 1921. La Universidad Popular José Martí fue fundado por Julio Antonio Mella en La Habana en el año 1923.

49 Julio Portocarrero. Sindicalismo peruano. Primer etapa. 1911 - 1930 (S.1., 1987) 87-92.

50 “Carta N 121 del Consejo Central del Partido Socialista del Ecuador, sección de la III Internacional Comunista al Secretario General de la Sección Latina de la Comintern”. Quito, 20 de julio de 1929. RGASPI.
}

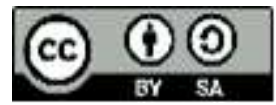


En 1929 el CEIC elaboró el plan de creación de una escuela partidaria para gran parte de los países de Amércia Latina con el objeto de "capacitar a militantes obreros, dirigentes y sustituir una parte de los dirigentes intelectuales pequeño-burgueses en los Partidos Comunistas de América Latina”. Para organizar este centro educativo el CEIC, envió a Buenos Aires a su colaborador, el austríaco Fritz Glaubauf, quien fue designado instructor de las escuelas partidarias bajo la tutela del SSAIC. Desde el principio, el proceso de creación de estas escuelas de cuadros se topó con muchas dificultades. El problema principal fue el Golpe de Estado emprendido por el general José Félix Uriburu en Argentina, que dio paso a un gobierno castrense entre 1930-1932. Tras el golpe, el SSAIC tuvo que mudar su sede a Montevideo, donde empezó a funcionar la escuela comunista continental. Sin embargo, según podemos concluir de los documentos de la Comintern, la actividad de la escuela en Uruguay fue bastante insignificante.

Esta situación no satisfizo a la Comintern, sobretodo porque frenaba las actividades de los Partidos Comunistas latinoamericanos. Dos años después el Secretariado Latinoamericano volvió a su idea antigua, sin embargo, el proyecto fue modificado sustancialmente. Victorio Codovilla propuso crear tres escuelas: en Uruguay (para Uruguay, Argentina, Chile, Bolivia, Perú y Paraguay), Brasil (solamente para el Partido Comunista de Brasil) y en los EE.UU. (para Ecuador, Colombia, Venezuela, América Central, Cuba y México). Este plan tampoco fue realizado de manera sistemática. Sin embargo, una escuela partidaria fue creada en Santiago de Chile. Allí estudiaron militantes comunistas chilenos, brasileños, peruanos, paraguayos y bolivianos. En 1935, tras del arresto de los profesores y estudiantes y después del inicio de la investigación judicial, la escuela fue cerrada ${ }^{51}$. Algunos militantes comunistas del Caribe lograron estudiar en la escuela fundada por el PCEU, pero, sobretodo, se trató de los puertorriqueños o cubanos que estaban militando en el PCEU y no de estudios organizados para comunistas latinoamericanos.

Los órganos de la Comintern no solo hacían convocatorias para estudiantes a las Escuelas de cuadros; también sistematizaron las admisiones y analizaron la efeciencia de los estudios. Estas labores se hicieron más notables cuando Georgi Skalov llegó a dirigir el Secretariado Latino-Americano. En los planes de trabajos de este Secretariado figuraban entre otras cosas- los análisis sobre los cuadros de los Partidos de México, Argentina, Cuba, Brasil, Chile y Perú, lo que incluía un censo de cuadros, desde el nivel de los Comites Centrales, las JJ.CC., hasta los Comites Regionales y las fracciones comunistas en los sindicatos; el estudio del desempeño práctico de los egresados de la ELI y de la KUTV en sus países, y la elaboración de las características de los estudiantes y egresados de esas escuelas de cuadros (algunas personas deberían ser especialmente invitados con el objeto de

F. 495, inv. 67, exp. 8, fs. 53 - 53 dorso; "Carta del CC del PSE, sección de la Internacional Comunista al Secretario General de la Sección Latina de la Internacional Comunista". Quito, 10 de agosto de 1929. RGASPI. F. 495, inv. 67, exp.8, f. 57 dorso.

${ }^{51}$ Fritz Glaufbauf. Mon travail a l'ecole d'Arcueil du Parti Comuniste Français. Cahiers d'histoire de l'Institut Maurice Thorez. №7 (1974): 154. 
consultarles), además del análisis de la educación comunista en Sudamérica y en América Central $^{52}$.

Obviamente, la carencia de estos análisis era visible, como lo indica la carta de unos de los dirigentes del Secretariado Latinoamericano del CEIC, el italiano "Maggi", al BSA de la Comintern:

Uds. escriben que "los compañeros que regresan de las escuelas y del Profintern vienen con ánimos bastante malos". ¿Que pasa? Quién, con qué ánimos precisamente, en qué se ha reflejado estos ánimos etc. El ejemplo de Gubinelli es único y bastante viejo. Nosotros hacemos trabajo con los que se van, pero, cómo podemos tomar en cuenta lo que Uds. piensen si, Uds. mismos, no nos dicen ninguna cosa concretamente. Subrayamos la casi completa imposibilidad de utilizar una tal información por parte de $\mathrm{Uds}^{53}$.

La Comintern intentaba convencer que el caso de "Gubinelli", Heitor Ferreira Lima, estudiante brasileño graduado de la ELI en 1930 (fue echado del CC del PCB por mantener cercanía con L.C.Prestes y luego fue expulsado del PCB), era una excepción. Sin embargo, era autoengaño: los colaboradores del Secretariado Latinoamericano estaban enterados de la ruptura del PC de Cuba y Sandalio Junco (que había estudiado en la ELI y se hizo trotskista), sobre la expulsión del PC de Colombia de Guillermo Hernández Rodríguez (¡su secretario general!) y de su esposa Carmen Fortoul (ambos graduados de la ELI), sobre la deserción del colombiano Diego Mejía, y de que el brasileño Mario Pedrosa se había convertido en trotskista. Todos estos casos eran bien conocidos en Moscú y algunos de estos habían sido objeto de discusiones y de correspondencia entre la Comintern y los Partidos respectivos. Sin embargo, el Partido Comunista mundial prefirió hacer caso omiso a los ejemplos mencionados, abogar por su inexistencia o a hacer creer que los asuntos se debían por falta de informaciones recibidas desde el subcontinente.

La gran mayoría de los estudiantes latinoamericanos -unos cién- llegó a la ELI a partir del año 1931. Este aumento espectacular fue debido a la mayor atención que la Comintern prestó a América Latina; sin embargo, hay que tener en cuenta que el volumen total de cuadros en formación en la Comintern -y no solo el sector latino y latinoamericano- creció enormemente en aquellos años, antes de caer bruscamente en los años 1935/1936. La convocatoria más grande de latinoamericanos a la ELI (22 estudiantes), de $1936^{54}$, resultó ser la última.

Ya a inicios de 1933 era visible el enojo de la Comintern respecto de los resultados de las convocatorias previas para la ELI:

\footnotetext{
52 "El plan de labores del Lender-Secretariado Latinoamericano sobre los cuadros partidarios (abril-junio de 1932)". Moscú, 1 de abril de 1932. RGASPI. F. 495, inv. 79, exp. 168, f. 59.

53 “Carta de Maggi al Buro Sud-Americano”. Moscú, febrero de 1933. RGASPI. F. 495, inv. 79, exp. 188, f.13.

54 "Nota del departamento de personal de la ELI (Volkov) a la Comisión Central de Control del CEIC (Müller)". Moscú, 25 de noviembre de 1936. RGASPI. F. 531, inv. 1, exp. 185, F. 18.
} 
Consideramos necesario constatar que la convocatoria de alumnos para nuestra escuela central para el año 1932-1933 resultó dar resultados insatisfactorios. Ninguna de nuestras secciones en los países de América del S. y del C. cumplió con su cuota y tampoco usó las condiciones extremamente favorables para formar los cuadros necesarios. Efectivamente, la tarea importantísima no fue realizada. Y aún menos podríamos tolerarlo tomando en cuenta que nuestras sucursales carecen fuertemente de cuadros preparados. $<\ldots>$ Algunos estudiantes tienen experiencia insuficiente del trabajo entre las masas y poca antigüedad de militancia en el partido. En algunos casos no se tomaba en cuenta su orígen social <...> La mayoría de los alumnos no tenía nada de capacitación teórica y no estuvo vinculada con las masas. Todo esto dificulta enormemente sus estudios en la escuela y no asegura de que estén formados los cuadros apropiados para nuestros secciones. ${ }^{55}$

Una vez más la Comintern exigió que por lo menos unos $25 \%$ de los estudiantes fueran de orígen indígena o negro, y de que mayoría de los representantes debían ser trabajadores de grandes industrias. Otro cuarto de los estudiantes fue reservado para la cuota femenina. Moscú estuvo preocupado con tener solo un representante chileno y solo un peruano e insistía que la cuota de ambos países debía ser prioritaria.

En 1934 la Comintern precisó las cuotas de envio de alumnos para 1935-1936, para varios países: a México le correspondían 4 plazas (incluyendo una mujer y un militante de la FJC), a Cuba 5 plazas (incluyendo una mujer y un militante de la FJC), a Colombia 3 plazas (incluyendo una para la FJC), a Venezuela y Costa Rica, 1 plaza para cada país, mientras tanto, a Panamá le tocó sólo una plaza para un representante de FJC. Dadas las diferentes condiciones en estos Partidos, Moscú estableció reglas variadas sobre la antigüedad mínima de militancia:

México: para obreros, no menos de 2 años; campesinos, 3 años; empleados e intelectuales, 4 años.

Cuba: para obreros $1 \frac{1}{2}$; campesinos, no menos de 4 años; para los demás, 3 años. Igual para COLOMBIA.

Venezuela. Costa Rica y Panamá: a consideración de los CC., respectivos, pero la antigüedad no menor de 1 año para los obreros y campesinos, y de $1 \frac{1}{2} 2$ años para los demás ${ }^{56}$.

Otro requisito fue la experiencia del trabajo dirigente en el PC o en la JC (no menos de un año en los casos mexicano, cubano y colombiano). Los criterios para Venezuela, Costa Rica y Panamá, eran menos estrictos, tomando en consideración la escasez de militantes.

\footnotetext{
55 “Carta del Lender-Secretariado a los Bureaus Sudamericano y del Caribe”. Moscú, 28 de abril de 1933. RGASPI. F. 495, inv. 79, exp. 188, f. 51.

56 "Carta de Sinani al Buro del Caribe de la Comintern”. Moscú, noviembre de 1934. RGASPI. F. 495, inv. 79, exp. 203, fs. 10-11.
} 


\section{El balance de los trabajos de las escuelas cominternistas para America Latina}

Casi 130 representantes del movimiento comunista latinoamericano estudiaron en las escuelas de cuadros. Se consiguió identificar a 121 estudiantes de la ELI, KUTV y escuelas militares. La mayoría de ellos formaron parte de la ELI. Apenas una docena cursaron la KUTV (de un estudiante panameño, Pablo Cordero, no se pudo averiguar si estudiaba en la ELI o en KUTV); además, el brasileño Carlos Augusto da Silva, logró estudiar en ambas escuelas: ELI y KUTV. Solamente un estudiante procedente de América Latina, Miklos Steinmetz, de Argentina, fue enviado a KUNMZ (dado sus orígenes húngaros) y se graduó en esta escuela.

Existe información, como mínimo, sobre otros 9 estudiantes del sector "L" que, por ahora, son conocidos sólo bajo sus seudónimos. Como a veces los comunistas extranjeros que llegaban a Moscú tenían varios nombres partidarios, es probable que alguno de ellos ya esté en la lista inicial.

Echando un vistazo a los contingentes de cursantes por los países latinoamericanos, se observa que la distribución de los mismos por países correspondió, más o menos, al estatus de uno u otro Partido Comunista en el país respectivo y a la fuerza o debilidad de la izquierda nacional. A la cabeza se encontraba el grupo cubano (24 estudiantes en total), sin embargo no queda claro si efectivamente fueron a Moscú otros cinco recomendados para los estudios. Un cubano (Sandalio Junco) fue enviado a la ELI dentro de la cuota mexicana. Siguieron los mexicanos, con 21 militantes. De este número, no queda claro si realmente fue a Moscú uno de los militantes del PCM recomendado por su partido. El número incluye al peruano Nicolás Terreros López, enviado a la ELI por los comunistas mexicanos. El grupo brasileño también era bastante numeroso; podría ser un poco más grande, sin embargo, un militante, Cristiano Cordeiro Coutinho, nunca fue a Moscú (por su propia decisión) a pesar de ser recomendado por el PCB.

De los argentinos, 18 fueron a la URSS. Este número incluye a Elena Kaifman recomendada para los estudios en Moscú, no obstante no hay claridad completa si ella logró llegar a la sede mayor de la revolución mundial. Se conoce por lo menos de un caso de militante argentino (Eduardo Sabato) que fue enviado a la URSS, pero nunca llegó a Moscú debido a que se había desilusionado en las ideas comunistas. Cabe notar que un argentino más, Jorge Paz (Armando Guerra) estudiaba en la ELI como representante del PC de los EU (en su país natal fue expulsado del PCA por chispista).

Luego estuvo el grupo colombiano (13 alumnos) y un elenco un poco menor del Uruguay (unas 9 personas) y de Venezuela (6 estudiantes). De estos últimos, no hay claridad si Balbino Acosta fue a estudiar o solo fue recomendado. Al grupo venezolano habría que agregar a Eduardo Machado ("Peralta"), enviado a la ELI por el PCEU.

Con cifras menores aparecen Ecuador (4 estudiantes, uno de los cuales no terminó sus estudios por enfermarse seriamente en la URSS), Panamá (3 estudiantes), Puerto Rico (3 estudiantes) Este número puede ser exagerado pues tres puertorriqueños fueron recomendados por el PCPR, no obstante, no hay claridad si dos de ellos efectivamente llegaron a la URSS. Chile, Perú y El Salvador, aparecen con 2 estudiantes cada uno (En 
caso de contar a N.Terreros como peruano, la cantidad del Perú aumenta a 3 personas), Paraguay, 1 ó 2 estudiantes ${ }^{57}$, Panamá, Salvador y Costa Rica, un estudiante de cada país.

Algúnos países, como Nicaragua y Bolivia, no comisionaron ningún estudiante. El boliviano Tristan Maroff, recomendado para los estudios por el PC de México, al final de cuentas fue rechazado por el CEIC, al ser considerado "renegado" y "traidor", quedando Bolivia sin estudiante.

De otros 9 estudiantes del sector latinoamericano de la ELI no hay certeza sobre su país de orígen. Por lo menos en tres casos los posibles estudiantes no fueron aceptados en la ELI, por causas diferentes: mientras el boliviano T. Maroff fue considerado persona indeseable, la uruguaya de orígen ruso, Evdokia Kravchenko, no fue admitida exclusivamente porque su dominio del idioma ruso hacía posible sus estudios en las escuelas nacionales soviéticas. Sorpresivamente, no fue aceptado el secretario general del PC de Panamá, Eliseo Echevez. Los documentos no contienen alguna justificación de esta decisión del CEIC, pero suponemos que Moscú consideraba que fuera necesario que siguiera su militancia dentro de Panamá.

La meta de asegurar la procedencia obrera de los alumnos nunca fue alcanzada en el caso latinoamericano. Según datos disponibles, los alumnos de procedencia obrera (o de familias de obreros agrícolas) no excedían el número de 35 personas, o sea, un poco más de 25\%; el siguiente grupo eran los alumnos de orígen pequeño burgués (27), le seguía el grupo de alumnos de orígen campesino (24), unos 5 estudiantes nacieron en familias aristócratas o de clase media; la procedencia social de casi el $30 \%$ de los alumnos es desconocida $^{58}$. De las 86 personas cuya profesión se pudo averiguar, los dos grupos más numerosos eran los carpinteros y sastres (7 cada uno), les seguían obreros ferroviarios y tabaqueros (6 cada uno), eléctricos y estudiantes (5 cada uno), obreros textiles, obreros agrícolas y obreros de construcción (4 cada uno), obreros metalúrgicos, zapateros, periodistas y choferes ( 3 cada uno), linotipistas, fogoneros, mecánicos, panaderos, obreros mueblistas, joyeros, artistas, empleados (2 cada uno), 1 estenografista, 1 albañil, 1 mecánico de coches, 1 peluquero, 1 obrero petrolero, 1 minero, 1 médico, 1 obrero de cervecería, 1 obrero de frigorífico, 1 herrero, 1 estibador. Los cálculos demuestran que apenas la mitad de los alumnos correspondían a los criterios de la Comintern sobre las profesiones proletarias; obviamente, falta averiguar las profesiones de una docena de alumnos, sin embargo, suponemos que la tendencia sería la misma.

La cuestión sobre la eficiencia del sistema de capacitación de cuadros de la Comintern está sin resolver ¿Cumplieron los egresados latinoamericanos con las tareas planteadas ante ellos? Nos parece que el efecto positivo de las escuelas partidarias para los partidos comunistas, está sobrevalorado ${ }^{59}$. Durante los estudios en Moscú los estudiantes se

\footnotetext{
${ }^{57}$ No hay claridad si Obdulio Barthe estudiaba en la ELI (como se desprende de su carpeta personal en el Archivo de la Comintern, o estos datos se referían a la epoca posterior a la Segunda Guerra mundial). "Expediente personal de Obdulio Barthé". RGASPI. F. 495, inv. 250, exp. 1; "Expediente personal de S. Báez”. RGASPI. F. 495, inv. 250, exp. 16.

${ }^{58}$ Estadística elaborada por los autores.

59 Por ejemplo por Branko Lazitch. Véanse Branko Lazitch. "Les écoles de cadres du Comintern". En: Jacques Freymond. Contributions á l'histoire du Comintern (Genéve: Ed. Librarie Droz, 1965) 233-257.
} 
afiliaban al PCR (b) y, al menos hasta el año 1929, observaban y se enteraban de la lucha interna en el partido y de la eliminación sistemática de las tendencias opositoras.

Uno de los pocos testimonios sobre su conversió como comunista ejemplar durante la vida en la ELI, fue el que dejó el comunista colombiano Ignacio Torres Giraldo quien había sido miembro de la sección colombiana de la Comintern aún antes de que el Partido Socialista Revolucionario cambiara el nombre al Partido Comunista. El colombiano estuvo en Moscú cerca de 50 meses, tiempo que le tomó el proceso de 'olvido' de su 'pasado burgués' y de la militancia socialista revolucionaria, la que había sido considerada por la III Internacional como insuficientemente comunista. Para Torres Giraldo, fue la época del aprendizaje marxista y -aún más importante- de la capacitación como militante disciplinado, acostumbrado a percibir la realidad bajo la prisma del Estado Mayor de la Comintern. El colombiano fue a Moscú unos meses después del inicio de las «purgas» dentro del PSRC, organizadas por la delegación de la Comintern encabezada por el egresado de la ELI, Guillermo Hernández Rodríguez (“Guillén”); entre miembros del grupo hay que nombrar también a la venezolana Carmen Fortoul y al estadounidense John Kornfeder ("Joseph Zack"), otros dos egresados de la ELI. No se trataba sólo de expulsar del partido a algunos militantes incómodos que no se cuadraban con la nueva línea del PSRC (PCC). Los militantes que querían quedarse en el PCC, tenían que, según Torres Giraldo, 'liquidar el pasado', convirtiendose en auténticos comunistas ${ }^{60}$.

Las memorias de Torres Giraldo no contienen ni una sola palabra sobre cómo el militante comunista estaba liquidando su propio pasado, tampoco hay pormenores de su viaje a la URSS. La significación de su testimonio es de otra índole: demuestra los resultados de la conversión a la nueva fé. Página tras página cuenta los éxitos de la construcción socialista, la colectivización del campo y la formación de la «nueva gente soviética». Sin embargo, Torres Giraldo cometió una vez desviación de la nueva línea general y fue cuando habló sobre el arresto del dirigente del Secretariado Latinoamericano, Georgi Skalov:

¿Quien era Sinani, el Sinani que yo conocí? < ..> Sinani y yo no tuvimos ninguna relación distinta del trabajo. Me tenía cierta deferencia, me trataba muy respetuosamente. $<\ldots>$ Siendo oficial del ejército tzarista, se pasó con su gente, en un encuentro en la región de Kazan, a las filas revolucionarias. Participó desde allí en el frente popular en armas que defendía la patria soviética de la contrarrevolución interna y de la invasión imperialista de catorce países. $<\ldots>$ Siempre fue un oficial rojo vestido de uniforme militar y siempre portaba la Órden de Lenin, condecoración que había recibido en testimonio de sus merecimientos ${ }^{61}$.

En las memorias de Torres Giraldo no hay ninguna alusión a la triste historia de Skalov. Sorpresivamente, no lo condena (a diferencia de muchas memorias oficialistas de los militantes). De hecho, consideramos estas pocas líneas como una "rebelión silenciosa"

\footnotetext{
${ }^{60}$ Klaus Meschkat y Jorge Maria Rojas. Liquidando el Pasado: La izquierda colombiana en los archivos de Moscú (Bogotá: Ed. FESCOL, 2009).

${ }^{61}$ Torres Giraldo, Ignacio. Cincuenta meses en Moscú (Cali: Universidad del Valle, 2008) 238-239.
} 
del comunista colombiano que llegó a ser Secretario General de su partido. Tomemos en cuenta que sus palabras fueron publicadas en el período cuando el nombre de Skalov fue borrado por completo de la historia de la Comintern.

Tomando en cuenta algunos ejemplos relevantes de los partidos comunistas europeos $^{62}$, consideramos que la ELI (y lo mismo la KUTV) fueron para los militantes latinoamericanos no sólo "fraguas de cuadros" sino también "fábricas de disidentes". Así, los ejemplos de las carreras partidarias exitosas van junto a los casos de expulsión de los partidos. A fin de cuentas ¿qué dió la ELI al movimiento comunista latinoamericano? De acuerdo con los datos estadísticos, se pueden trazar algúnas tendencias. Pero, dado que no hay información sobre el paradero posterior de muchos graduados, es imposible hacerse una idea más o menos objetiva. Al mismo tiempo, la propia ausencia de datos permite ya sacar la conclusión de que muchos de ellos nunca llegaron a los puestos de dirigentes en sus partidos respectivos.

En la escuela estudiaron cuatro líderes comunistas latinoamericanos: Astrogildo Pereira (Brasil), Hernán Laborde (México), Eudocio Ravines (Perú), Ricardo Paredes (Ecuador). Luego, por diferentes razones, todos ellos fueron destituidos de sus cargos, y los tres primeros hasta expulsados de los partidos.

En la URSS se quedaron dos argentinos: Pedro Loss, que se casó con Daria Kravchenko y, tras participar en la Guerra Civil en España, trabajó en la industria aeronáutica de la Unión Soviética, y Jorge Paz, expulsado de la ELI y del PC en 1931. El cubano Rubén Calderío -hermano del Secretario General del PCC, Blas Roca, que se casó con Aurora Bezsmertnaia, hija de un emigrante que había regresado desde Argentina a la URSS y que también participó en la Guerra Civil en España- se quedó en Moscú por dos años.

Tras egresar de las escuelas de cuadros en Moscú, 26 estudiantes fueron miembros de los CC de sus partidos (para la mayoría de ellos significaba un ascenso en la carrera partidaria, aunque algunos ya habían ocupado este puesto antes); 7 entraron a los Burós Políticos, 2 fueron elegidos miembros suplentes del CC del PC, tres fueron elegidos secretarios de los CC, cuatro o cinco fueron Secretarios de Comités Regionales; uno llegó o ser miembro del CC de las FJC, mientras que 4 ocuparon puestos de secretarios generales de la FJC en sus países, y uno, segundo secretario de la FJC. Tres ex alumnos de las escuelas de cuadros dieron clases en las instituciones semejantes en sus países, y uno de ellos encabezó una de ellas (Pinjos Meshkop del PCC). Rodolfo Guzmán fue elegido Secretario General de la Confederación de Trabajadores de Costa Rica y José Alvaro ocupó puesto semejante en la Central Sindical del Ecuador. Cinco ex alumnos ocuparon cargos de Secretarios Generales de sus partidos: Gerónimo Arnedo Álvarez (PCA), Heitor Ferreira Lima (PCB), Guillermo Hernández Rodríguez e I. Torres Giraldo (PC de Colombia), Nicolás Terreros (PC del Perú). Mientras Arnedo Álvarez encabezó su partido durante 42 años, los demás no estuvieron mucho tiempo en los puestos dirigentes (Hernández

\footnotetext{
${ }^{62}$ Véanse para el caso suizo, Peter Huber. Stalins Schatten in die Schweiz. Schweizer Kommunisten in Moskau: Verteidiger und Gefangene der Komintern (Zurich 1994) 47-48, 303, 328. Para el caso alemán y austríaco, véanse Julia Köstenberger, Der deutsche Sektor an der KUNMZ in Moskau (1921-1936). Österreicher an einer Sowjetischen Kadershule, Diplomarbeit (Wien: Universität Wien, 1999) 194-201.
}

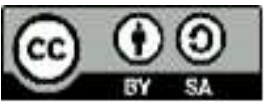


Rodríguez, Terreros y Ferreira Lima, fueron expulsados de las filas comunistas). En general, menos de la mitad de los latinoamericanos que fueron a estudiar en Moscú subieron de rango al interior de sus colectividades o en las FJC. A los casos de integración, ascenso eficaz y permanencia prolongada en los PC tras el regreso (el uruguayo L.A.Fierro ${ }^{63}$ y el argentino G.Arnedo Álvarez, sobre todo), hay que oponer fracasos inmediatos (Sandalio Junco ${ }^{64}$, Diego Mejía ${ }^{65}$ ) y rupturas a mediano plazo (Carmen Fortoul $^{66}$, Silo Furtado de Meireles y E.Machado).

15 graduados de la ELI (incluyendo varios secretarios generales de los PC y de la FJC) fueron expulsados (uno de ellos luego fue restablecido en las filas comunistas), en tanto que el mexicano Evelio Vadillo ("Pedro Arapos"), fue represaliado en la URSS pasando casi 20 años en la cárcel ${ }^{67}$. Según los datos disponibles, el arresto de Vadillo fue, originalmente, una cosa accidental. Tras la aparición de una consigna supuestamente trotskista en la pared de un baño de la ELI, en 1935, la Comintern inició una investigación interna teniendo serias sospechas sobre los estudiantes procedentes del PC de España ${ }^{68}$. Sin embargo, luego Evelio Vadillo se convirtió el sospechoso principal, entre otras cosas, porque fue considerado demasiado "liberal" y por la existencia de características negativas sobre él desde primeros días de su estancia en la ELI (aportadas por militantes de la FJC de España en Moscú). La secretaria técnica del Secretariado de América del Sur y del Centro, Olga Meshkovskaya que había sido detenida por el NKVD, nombró a Vadillo como miembro de su "grupo terrorista", lo que motivó la decisión de encarcelamiento del mexicano. La consigna trotskista ya no era el objeto de investigación: el militante del PCM fue acusado de guardar literatura contrarrevolucionaria recibida de Meshkovskaya y de formar parte de un complot terrorista en contra de los dirigentes del Partido Comunista Ruso. ${ }^{69}$.

Él fue el único latinoamericano -sin contar a los que habían recibido la nacionalidad soviética- que fue víctima del Comisariado del Pueblo para Asuntos Internos. Al parecer, hubo otro latinoamericano que cayó víctima de Stalin: nos referimos al argentino Jorge Paz ("Armando Guerra"), sin embargo, optó por recibir la nacionalidad soviética y no fue

\footnotetext{
${ }^{63}$ Luis Alberto Fierro («Horacio» en la ELI), uruguayo nacido en 1906, secretario de la Federación de las Juventudes Comunistas tras su regreso al país (1929). "Expediente personal de Luis Alberto Fierro". RGASPI. F. 495, inv. 267, exp. 6; "Expediente personal de Luis Alberto Fierro". RGASPI. F. 495, inv. 197, exp. 74.

64 Sandalio Junco (1894-1942), cubano, cursante en la ELI (1931-1932), rompió con el PC de Cuba tras su regreso. "Expediente personal de Sandalio Junco". RGASPI. F. 495, inv. 241, exp. 27.

65 Diego Mejía (1902-), «Roberto Rodríguez» en la MLS (1928-1931), regresó a Colombia sin reanudar contactos con el PC. "Expediente personal de Diego Mejía". RGASPI. F. 495, inv. 227, exp. 4.

${ }^{66}$ Carmen Fortoul Briceño (1893- ¿?), venezolana en la MLS (1927-1930), regresó a Colombia y formaba parte de la dirección de los PP.CC. de Colombia y de Venezuela. Fue expulsada del PCC (1933) junto con su esposo, el colombiano G.Hernández Rodríguez.

67 Héctor Aguilar Camín, "El camarada Vadillo", Nexos, México (marzo de 1990). http://www.nexos.com.mx/?p=5760; García Treviño, Rodrigo, "El regreso de Evelio Vadillo". Nexos. México (1 de diciembre de 1990). - http://www.nexos.com.mx/?p=6041; Gerardo Antonio Martínez. "Un comunista mexicano preso en Siberia". El Universal. México (20 de julio de 2013).

68 "Nota de Stella Blagoeva". Moscú, 28 de agosto de 1936. RGASPI. F. 531, inv. 1, exp. 185, F. 12.

69 “Comunicación de Mijailov”. Moscú, 25 de enero de 1936. RGASPI. F. 531, inv.1, exp. 185, f.5.
} 
considerado por NKVD como un extranjero. El paradero de Jorge Paz hasta hoy día es desconocido, ni siquiera sabemos la fecha de su arresto en la URSS. Sin embargo, en 1941 su nombre aparece en la lista de los prisioneros políticos evacuados desde Moscú a la cárcel de Ulianovsk. En esta misma lista figura el nombre de otro graduado de la ELI, el ex argentino de orígen ruso-judío, Abram Viniar (Vinner), quien había militado en el sindicato de muebleros antes de irse a la ELI y en la URSS fue enviado a trabajar como intérprete del Directorado de Inteligencia Militar. ${ }^{70}$ El venezolano Fernando Key Sánchez ("Santiago") corrió mejor suerte: a pesar de ser expulsado del PCV y de la ELI por la Comisión Internacional de Control de la Comintern a causa de una supuesta delación, logró no solo regresar a salvo a su patria, sino también fue, posteriormente, restablecido en las filas del Partido Comunista y llegó a ser uno de los dirigentes del PCV.

El brasileño León Piatigorsky (nació cerca de Odessa y luego emigró a Brasil), miembro del PCB y del CR de la FJCB, fue expulsado de Brasil por actividades revolucionarias y finalmente llegó a la URSS. Durante sus estudios en la ELI fue colaborador del Secretariado Latinoamericano del CEIC, luego fue purgado de la Comintern y trabajó en la Editorial de Trabajadores Extranjeros. Siendo ya ciudadano soviético, fue acusado por el representante de la FJCB ante el CE de la IJC de "destruir la organización de la FJCB" en Rio de Janeiro y, tras estas acusaciones, fue detenido en 1937 por NKVD, pasando cinco años en prisión por "contrarevolucionario". Liberado en 1942, en 1951 fue detenido de nuevo y exiliado a Siberia.

Otro brasileño (también de orígen ruso-judío) Gersh Berezin («Grigory Grishin»), quien fuera uno de los dirigentes del PCB y secretario del CR del PCB en Rio de Janeiro formando, al mismo tiempo, parte del CC del PCB, estudió dos años en la ELI (se graduó de la escuela en 1931). En 1933 le iban a enviar de regreso a Sudamérica para formar en Brasil un Sub-Comité del Bureau Sudamericano y como representante de la fracción comunista de la CSLA en este Sub-Comité. Sin embargo, por razones desconocidas, no fue a Brasil y se ocupó de trabajos en la Sección Latinoamericana de la Internacional Sindical Roja, formando parte del grupo que preparó la insurrección armada de la Alianza Nacional Libertadora, en 1935. Este mismo año fue expulsado de la Comintern como "elemento hostil". Normalmente los "purgados" luego fueron detenidos por NKVD, no obstante, no hemos encontrado aún alguna prueba de esto en el caso de Berezin.

Dos egresados de la ELI se convirtieron en líderes de organizaciones que se habían separado de los partidos comunistas: el cubano Sandalio Junco y el venezolano Eduardo Machado. El brasileño Mario Pedrosa, en los años 30, se unió a la oposición trotskista en Brasil.

De esa manera, la mayoría de los latinoamericanos que estudiaron en Moscú no llegaron a ser dirigentes superiores de los partidos. Los militantes de los PC's latinoamericanos no consiguieron ampliar el "banco de suplentes" dentro de la izquierda nacional, ni tampoco se cumplió la tarea principal que consistía en capacitar a los

\footnotetext{
70 "Materiales sobre la evacuación de los prisioneros políticos de las cárceles de Moscú (23 de junio de 1941 14 de febrero de 1942)". - GARF. F. P9413, inv. 1, exp. 24, fs. 35-36. http://notepad.memo.ru/r9413/1/24/materialy-po-evakuacii-zaklyuchennyh-iz-tyurem-moskvy-so-spiskamiarestovannyh
} 
dirigentes, adiestrándolos teórica y prácticamente. Obviamente, esta condición fue una de las razones para la que la Comintern decidiera suspender sus labores en este ámbito. En 1938 la ELI fue cerrada.

\section{Consideraciones finales}

A traves de este estudio, hemos analizado la participación de los militantes comunistas latinoamericanos en los cursos de las escuelas de cuadros de la Comintern. Este análisis deja en evidencia que la presencia latinoamericana en estas escuelas, aunque era notable, estuvo al mismo tiempo lejos de los tamaños previstos por los dirigentes de la III Internacional. Muestra también que las escuelas de cuadros de la Comintern (la ELI y la KUTV, sobretodo) no lograron alcanzar el objetivo principal de su trabajo en lo que se refería a América Latina: el número de egresados que llegaron a ser dirigentes de sus partidos nacionales, fue relativamente bajo. Peor aún para el Partido Comunista mundial, varios personajes que habían estudiado en Moscú, luego se convirtieron en opositores dentro de los partidos o rompieron con los comunistas, en general. Hemos investigado algunas causas del ineficiente trabajo de las escuelas cominternistas y de la falta de alumnos latinoamericanos en ellas, demostrando que los déficits en el proceso de selección de candidatos, tuvo mucho que ver con el sistema de toma de decisiones dentro de la Comintern. Según se desprende de nuestro análisis, la III Internacional intentó varias veces mejorar el sistema de capacitación de cuadros dirigentes, no obstante, estos proyectos o no se terminaron o no dieron los resultados esperados. Consecuentemente, las organizaciones comunistas latinoamericanas -a diferencia de Europa- vieron mermadas sus posibilidades de contar con cuadros formados en Moscú, lo que impactaría, obviamente, en su desarrollo, tanto en el período de la Comintern, como en la época posterior a la Segunda Guerra mundial, aspecto clave para la historia de las izquierdas latinoamericanas, tema que, por ahora, queda como un objeto de estudio adicional.

\section{FUENTES}

\section{ARCHIVOS:}

GARF Archivo Estatal de la Federación Rusa. Moscú (en ruso: ГАРФ)

RGASPI Archivo Estatal de Historia Social y Politica, Moscu (en ruso: РГАСПИ)

"El acuerdo del Buró Organizativo del CEIC". Moscú, 9 de octubre de 1924. RGASPI. F. 531, inv. 1, exp.1, f. 24.

"Carta de H. Balbino Acosta a G. Machado". Panamá, 17 de julio de 1930. RGASPI. F. 495, inv. 116, exp.6, f.18.

"Carta de Bertram D. Wolfe (Lender-Secretariado Latinoamericano) a los dirigentes de la ELI". Moscú, 17 de abril de 1929. RGASPI. F. 495, inv. 79, exp. 65, fs. 1-2.

"Carta del CC del PSE, sección de la III Internacional Comunista, al camarada Secretario General de la III Internacional Comunista". Quito, 9 de febrero de 1929. RGASPI. F. 495, inv. 67, exp.8, f. 7. 
"Carta del CC del PSE, sección de la Internacional Comunista al Secretario General de la Sección Latina de la Internacional Comunista". Quito, 10 de agosto de 1929. RGASPI. F. 495, inv. 67, exp.8, f. 57 dorso.

"Carta del CC del PSE, sección del III Intenacional Comunista al Secretario General de la Sección Latina del Comintern”. Quito, 20 de julio de 1929. RGASPI. F. 495, inv. 67, exp. 8, f. 54.

"Carta de Codovilla al Secretariado Latinoamericano de la Comintern". Buenos Aires, 5 de septiembre de 1928. RGASPI. F. 503, inv. 1, exp. 19, f. 38.

"Carta No 121 del Consejo Central del Partido Socialista del Ecuador, sección de la III Internacional Comunista al Secretario General de la Sección Latina de la Comintern". Quito, 20 de julio de 1929. RGASPI. F. 495, inv. 67, exp. 8, fs. 53 - 53 dorso.

"Carta de Ercoli (P. Togliatti) al Secretariado del Partido Comunista de Argentina". Moscú, 6 de julio de 1926. RGASPI. F. 495, inv. 134, exp.77, f. 144.

"Carta de Ercoli (P. Togliatti) al SSAIC". Moscú, 11 de junio de 1926. RGASPI. F. 503, inv.1, exp. 7, f. 2.

«Carta del Lender-Secretariado del CEIC a los Burós Sudamericano y del Caribe ». Moscú, 28 de abril de 1933. RGASPI. F. 495, inv. 79, exp. 188, fs. 51-53.

"Carta de Lucas E. Ibarrola a la Comintern". 12 de abril de 1929. RGASPI. F. 495, inv. 117, exp. 6, f. 36 .

"Carta de L. E. Ibarrola al Secretariado de la Comintern". Asunción, enero de 1929. RGASPI. F.495, inv. 117, exp. 6, fs. 25-27.

"Carta de Maggi al Buro Sud-Americano". Moscú, febrero de 1933. RGASPI. F. 495, inv. 79, exp. 188, f.13.

"Carta de M. Frumkina a Pyatnitskii, Manuilskii, Knorin, Krayevskii". Moscú, 12 de febrero de 1935. RGASPI. F. 495, inv. 20, exp. 862, f. 7.

"Carta de Pedro Romo, secretario general del PCA, a los camaradas del Comité Ejecutivo de la Internacional Comunista". Buenos Aires, 23 de julio de 1926. RGASPI. F. 495, inv. 134, exp. 78, f. 100 .

"Carta del Secretario General del PCM, H. Laborde, al Secretariado Sudamericano". México, 15 de agosto de 1930. RGASPI. F. 495, inv. 108, exp.131, f. 84.

"Carta del Secretario General del PCM, H. Laborde, al Secretariado Sudamericano de la Comintern”. México, 17 de junio de 1930. RGASPI. F. 495, inv. 108, exp. 131, f. 76.

"Carta del Secretariado Latino del CEIC a la Universidad Oriental". Moscú, 26 de junio de 1928. RGASPI. F. 495, inv. 32, exp.35, f. 209.

"Carta del Secretariado Latinoamericano del CEIC al Buró Sudamericano del CEIC". Moscú, junio de 1931. RGASPI. F. 495, inv. 79, exp.153, f. 54.

"Carta del Secretariado Sudamericano (Garlandi) a la Comisión Política del CEIC". Moscú, 25 de enero de 1930. RGASPI. F. 495, inv. 79, exp.112, f. 31.

"Carta de V. Codovilla a R. Martínez de la Torre". Buenos Aires, 29 de marzo de 1929. RGASPI, F. 495, inv. 118, exp.6, f. 11.

"Carta de Sinani al Buro del Caribe de la Comintern". Moscú, noviembre de 1934. RGASPI. F. 495, inv. 79, exp. 203, fs. 10-11. 185, f.5.

"Comunicación de Mijailov". Moscú, 25 de enero de 1936. RGASPI. F. 531, inv.1, exp.

"Decisión del Secretariado del CEIC". Moscú, 9 de octubre de 1924. RGASPI. F. 495, inv. 18, exp.1109, f.13.

"Estructura del sector "L". Oficio del jefe del sector "L", L. Mikhailov". Moscú, 19 de febrero de 1936. RGASPI. F. 531, inv. 1, exp.185, fs. 16-17.

"Expediente personal de Antonio Kantor". RGASPI. F. 495, inv 190, exp.35. 
“Expediente personal de Diego Mejía”. RGASPI. F. 495, inv. 227, exp. 4.

"Expediente personal de Luis Alberto Fierro". RGASPI. F. 495, inv. 267, exp. 6.

"Expediente personal de Luis Alberto Fierro". RGASPI. F. 495, inv. 197, exp. 74.

"Expediente personal de Obdulio Barthé". RGASPI. F. 495, inv. 250, exp. 1.

"Expediente personal de Ramón Nicolau". RGASPI. F. 495, inv. 230, exp. 15.

"Expediente personal de S. Báez". RGASPI. F. 495, inv. 250, exp. 16.

"Expediente personal de Sandalio Junco". RGASPI. F. 495, inv. 241, exp. 27.

"Expedientes del transfer al PCR (b)". RGASPI. F. 17, inv. 98, exp. 830, fs. 1-4.

"Informe de la delegación del PCM (M. Díaz Ramírez) en el VI Congreso de la Internacional Comunista”. México, 20 de noviembre de 1928. RGASPI. F. 495, inv. 108, exp. 83, f. 19.

“Listados de los estudiantes de la ELI de 1926 a 1931”. RGASPI. F. 531, inv. 1, exp.31, fs. 7-33.

"Nota del departamento de personal de la ELI (Volkov) a la Comisión Central de Control del CEIC (Müller)". Moscú, 25 de noviembre de 1936. RGASPI. F. 531, inv. 1, exp. 185, F. 18.

"Nota de Stella Blagoeva". Moscú, 28 de agosto de 1936. RGASPI. F. 531, inv. 1, exp. 185, F. 12.

“Oficio de Béla Kun al Presidium del CEIC". Moscú, 3 de octubre de 1925. RGASPI. F. 495, inv. 30, exp.69, f. 1.

"El plan de labores del Lender-Secretariado Latinoamericano sobre los cuadros partidarios (abril-junio de 1932)". Moscú, 1 de abril de 1932. RGASPI. F. 495, inv. 79, exp. 168, f. 59.

"Reunión del Grupo nacional latino Americano, realizada el 12/3/30". RGASPI. F. 531, inv. 1, exp. 182a, fs.1-4.

"Sugerencias del Secretariado Latinoamericano respecto al trabajo en América Latina". Moscú, 2 de agosto de 1929. RGASPI. F. 495, inv. 79, exp. 66, fs. 37-38.

“Telegrama de R. Paredes a E. Terán”. S.f.. RGASPI. F.495, inv. 67, exp. 1, f. 42.

\section{PRENSA:}

Izvestia TsK RKP/b/, Moscú

Jährbuch für Historische Kommunismusforschung, Köln

Memoria, México

Militante Comunista, La Habana

Narody Azii i Afriki, Moscú

Voprosy istorii KPSS, Moscú

\section{RECURSOS ELECTRONICOS:}

Aguilar Camín, Héctor, "El camarada Vadillo", Nexos, México, núm. 147, 1 de marzo de 1990. http://www.nexos.com.mx/?p=5760.

COMINTERN Electronic Archives (www.comintern-online.com)

García Treviño, Rodrigo, "El regreso de Evelio Vadillo", Nexos, México, 1 de diciembre de 1990. http://www.nexos.com.mx/?p=6041

Krekola, Jonni. A Short Course of Stalinism: Finns at the International Lenin School, Moscow, 1926-1938. Doctoral Dissertation. - https://helda.helsinki.fi/handle/10138/11969

"Materiales sobre la evacuación de los prisioneros politicos de las cárceles de Moscú (23 de junio de 1941-14 de febrero de 1942)". - Archivo Estatal de la Federación Rusa (GARF por sus siglas en ruso). F. P9413, inv. 1, exp. 24, fs. 35-36. - http://notepad.memo.ru/r9413/1/24/materialypo-evakuacii-zaklyuchennyh-iz-tyurem-moskvy-so-spiskami-arestovannyh

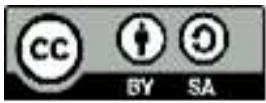


Pantsov, Alexander V. and Spiachak, Daria. Chinese Students at the International Lenin School in Moscow, 1926-1938: Light from the Russian Archives. E-book, vol. 81, 2014. http://booksandjournals.brillonline.com/content/books/b9789004282278_025

\section{BIBLIOGRAFIA:}

Adibekov, Grant Mijailovich, Shajnazarova, Eleonora Nikolaevna, Shirinia, Kirill Kirillovich. Organizatsionnaia struktura Kominterna. 1919-1943. Moscú: Rosspen, 1997.

Babitschenko, L. "Die Kaderschulung der Komintern". Weber, Hermann et al. (eds.). Jährbuch für Historische Kommunismusforschung, Berlin,1993, 37-59. Press, 1987.

Caballero, Manuel. Latin America and the Comintern. Cambridge: Cambridge University

Carrillo, Rafael. "Memoria roja de los años veinte. El testimonio de Rafael Carrillo". Memoria. Mensual de Política y Cultura, núm.92, México, 1992.

Cohen, Gidon and Morgan, Kevin. "Stalin's Sausage Machine: British Students at the Internatonal Lenin School 1926-37”. Twentieth Century British History, vol. 13, N. 4, 2002, 327355.

"Deyatelnost' Kommunisticheskij partii v dele formirovaniia i podgotovki. Resheniie IV Kongressa Kominterna”. En Kommunisticheskii Internatsional v dokumentaj. 1919-1932. Moscú: Partiinoie izdatelstvo, 1933, $336-337$.

Ferreira Lima, Heitor. Caminhos Percorridos. Memoria de militância. S.1, 1982.

Gavrikov, Yuri P. Sovest' Peru. Moscú: Politizdat, 1987.

Glaufbauf, Fritz. "Mon travail a l'Ecole d'Arcueil du Parti Comuniste Français". Cahiers d'histoire de l'Institut Maurice Thorez, núm. 7, Paris, 1974.

Goldenberg, Boris. Kommunismus in Latein Amerika. Stuttgart, Berlin, Köln, Mainz: W.Kohlhammer, 1971.

Lazar Jeifets y Víctor Jeifets. América Latina en la Internacional Comunista, 1919-1943. Diccionario Biográfico. Santiago de Chile: Ariadna Ediciones, 2015.

Jeifets, Lazar, Victor Jeifets y Peter Huber. La Internacional Comunista y America Latina, 1919-1943. Diccionario biografico. Moscu: Instituto de Latinoamerica de la Academia de Ciencias / Ginebra: Institut pour l'histoire du communisme, 2004.

Halstead, John and Mc Loughlin, Barry. "British and Irish Students at the International Lenin Sc (Yearbook of the Irish Labour History Society) 22(1997),pp.63-79hool 1926-37”. Saothar. Yearbook of the Irish Labor History Society, N.22, 1997, 63-79.

Huber, Peter. Stalins Schatten in die Schweiz. Schweizer Kommunisten in Moskau: Verteidiger und Gefangene der Komintern. Zurich: Chronos, 1994.

Kocho-Williams, A. Stalin's Students: the International Lenin School, 1926-1938. http://www.academia.edu/5615677/Stalin_s_Students_the_International_Lenin_School_1926-1938

Köstenberger, Julie. Der deutsche Sektor an der KUNMZ in Moskau (1921-1936). Österreicher an einer Sowjetischen Kadershule. Diplomarbeit. Wien: Universität Wien, 1999.

Köstenberger, Julie. "Die Geschichte der Kommunistischen Universität der nationalen Minderheiten des Westens (KUNMZ) in Moskau 1921-1936". Jährbuch für historische Kommunismusforschung, núm.???, Köln, 2000/2001 (2001).

Köstenberger, Julie.’Die Internationale Lenin-Schule 1926-1938). En: Buckmiller, Michael and Meschkat, Klaus (eds.). Biographisches Handbuch zur Geschichte der Kommunistischen Internationale: Ein deutsch-russisches Forschungsprojekt. Berlin: Akademie Verlag, 2007, 287309.

Lazitch, Branko. "Les écoles de cadres du Comintern". En: Freymond, Jacques. Contributions á l'histoire du Comintern. Genéve: Ed. Librarie Droz, 1965, 233-257. 
Mariátegui, José Carlos. Siete ensayos de interpretación de la realidad peruana. Moscú: Izdatelstvo Inostrannoi literatury, 1963.

Martínez, Gerardo Antonio. "Un comunista mexicano preso en Siberia", El Universal, México, 20 de julio de 2013.

Meshkat, Klaus y Rojas, Jorge María. Liquidando el pasado: La izquierda colombiana en los archivos de Moscú. Bogotá: Ed. FESCOL, 2009.

Piatyi Mirovoi kongress Kommunisticheskogo Internatsionala. 17 iyunia-8 iyuilia $1924 \mathrm{~g}$. Stenograficheskii otchet. Parte 2. Leningrado: Gosizdat, 1925.

Portocarrero, Julio. Sindicalismo peruano. Primer etapa. 1911-1930. S.1.: s.e., 1987.

Sokolov, A.A. Comintern i Vietnam. La Preparación de los cuadros politicos vietnamienses en las escuelas superiores comunistas de la URSS. Los años '20-'30. (Un ensayo histórico y político. Moscú: Institut Vostokovedeniia RAN, 1998.

Sorkin, G.Z. y Shirinia, K.K. "Comintern - escuela de formación internacionalista de cuadros". Voprosy istorii KPSS, núm. 1, Moscú, 1977.

Timofeeva, N.N. "La Universidad Comunista de los Trabajadores de Oriente (KUTV) (1921-1925)". Narody Azii i Afriki, núm. 2, Moscú, 1976.

Timofeeva, N.N. "La Universidad Comunista de los Trabajadores de Oriente (KUTV) (1926-1938)”. Narody Azii i Afriki, núm. 5, Moscú, 1979.

Torres Giraldo, Ignacio. Cincuenta meses en Moscú. Cali: Universidad del Valle, 2008.

Olga Ulianova y Alfredo Riquelme. Chile en los archivos soviéticos. Tomo 1. Chile y Komintern 1922-1931. Santiago: Ed. LOM, 2005; tomo 2. Chile y Komintern 1931-1935. Santiago: LOM, 2009

Olga Ulianova (ed.). Políticas, redes y militancias. Chile y América Latina en el siglo XX. Santiago: USACH-Ariadna, 2009

Olga Ulianova, Manuel Loyola y Rolando Álvarez (eds.). 1912-2012: El siglo de los comunistas chilenos. Santiago: Ariadna, 2012. 